ARTICLE

https://doi.org/10.1057/s41599-019-0226-9

\title{
Translating antimicrobial resistance: a case study of context and consequences of antibiotic-related communication in three northern Thai villages
}

\author{
Nutcha Charoenboon (D) et al. ${ }^{\#}$
}

\begin{abstract}
Antimicrobial resistance (AMR) threatens to cause ten million deaths annually by 2050, making it a top item on the global health agenda. The current global policy response is multi-faceted, wherein behavioural dimensions like people's medicine use are being predominantly addressed with education and communication campaigns. The social sciences literature suggests that cross-contextual translation of medical knowledge in global awareness campaigns can create misunderstandings and adverse behavioural responses. However, the consequences of AMR communication in low-income and middle-income contexts remain largely undocumented. In response to the empirical knowledge gap, this study presents the case study of educational activity in three northern Thai villages with the objective of contributing to the understanding of the consequences (and their contextual influences) when sharing antibioticrelated information in a rural middle-income setting. The activity's messages were based on World Health Organization AMR awareness-raising material. A mixed-methods research design informed the analysis. Descriptive difference-in-difference and geographical analysis based on complete village census surveys with a 3-month interval $(n=1096)$ was supplemented by qualitative data and observations from the educational activity. The underlying conceptual framework hypothesised that outcomes arise via (a) direct participation and indirect exposure (posters, conversations), subject to translational processes and physical and health system contexts; and via (b) the activity's influence on village social networks. The outcomes demonstrated that participants aligned their antibiotic-related attitudes and behaviours with the activity's recommendations. Aside from language barriers (which excluded non-Thai speakers), fragmented local healthcare landscapes limited villagers' ability to act on the activity but also provided a market opportunity for informal antibiotics sales, and interactions with parallel yet misunderstood public health campaigns created rumours and resistance. Social support from community members also promoted healthy behaviours but remained unaffected by the activity. As one of the most detailed mixed-method assessments of public engagement in AMR, this study challenges the current dominance of awareness-raising campaigns to change population behaviours. We call for comprehensive mixed-method evaluations of future campaigns, mandatory twodirectional knowledge exchange components, and alternative behaviour change approaches that respond to contextual constraints like precarity rather than alleged knowledge deficits.
\end{abstract}




\section{Introduction}

"We need to: 1. Undertake a massive global public awareness campaign"

(The Review on Antimicrobial Resistance, 2016, p. 17)

ducation and awareness raising are a standard component of global policy approaches to change behaviour in the context of antimicrobial resistance (AMR), but, considering the proposed global scale of intervention, our knowledge on relevance, impact, and side-effects of AMR communication is worryingly inadequate. Often framed as a form of "public engagement" (Howard et al., 2013; Roh et al., 2018; Allison et al., 2017), ${ }^{1}$ AMR education and awareness activities involve presenting medical knowledge to the general public. This process of translating technical into popular language faces formidable challenges like sender-recipient dynamics, misunderstanding, attribution of blame to the "ignorant" public, and adverse and/or unforeseen public reactions with inequitable outcomes on healthcare utilisation (Davis et al., 2017; Lambert, 2016, paragraph 8; Peter and Koch, 2016; Carrion, 2018; Dawson, 2018).

Cross-contextual communication of AMR complicates this problem yet further (Mendelson et al., 2017). Our own previous AMR-related qualitative research in Southeast Asia showed us that technical medical language is unsuitable for communication with the general public. During field research in rural northern Thailand and urban Myanmar, we observed that the medical language used in healthcare settings (e.g. primary care units, hospitals) was often difficult to understand for members of the general population, but also that language barriers extended beyond linguistics into the underlying conceptions of illness and medicine (Khine Zaw et al., 2018; Haenssgen et al., 2018a). For example, the idea of an "antibiotic" or "antimicrobial" is more difficult to absorb in the absence of bacteria and viruses as disease-causing agents in the popular understanding of medicine in Thailand (Tangcharoensathien et al., 2018). The introduction of new terms for commonly used medicine could then potentially spark interest and a desire to learn more, but it could also remain unintelligible or, worse, create confusion that can change behaviours in unintended and harmful ways. However, the assessment of these challenges and their associated impacts and contextual factors is complicated because methods to evaluate the effectiveness of public engagement in global health have developed slowly-especially where public engagement expands beyond the instrumental purpose of raising awareness or changing behaviour (Lafrenière and Cox, 2013; Galloway, 2009; Etherton and Prentki, 2006; Ledgard, 2013, 2016).

In response to the empirical knowledge gap, our objective in this paper was to contribute to the understanding of the consequences (and their contextual influences) when sharing antibiotic-related information in a rural middle-income setting. We aimed to achieve this objective through a mixed-method assessment of an antibiotic-themed public engagement activity in three northern Thai villages. As a form of public engagement (rather than a behaviour change intervention), the intention of the half-day activity was not to alter supposedly "inappropriate" behaviour, but merely (a) to share ideas about antibiotic resistance based on material from the World Health Organization (WHO) and (b) to learn about villagers' experience in medicine use and their understanding of these messages. Our theme of "translating AMR" thereby pertained to our conversion of WHO material on AMR into messages that were more compatible with local notions of illness and medicine, ${ }^{2}$ but also to the continued and ungoverned translation and interpretation of these messages among villagers during and after the educational activity. The research questions that guided our enquiry (justified by the review of background literature in the section "Background") focussed on the knowledge-sharing element of the activity (i.e., ideas about antibiotic resistance):

RQ1. What are the direct and indirect consequences of an AMR-related educational activity on villagers' health-related attitudes and behaviours?

RQ2. Which contextual factors explain these outcomes and their distribution?

Our mixed-methods study design provided us with a unique opportunity to assess the consequences of the educational activity. Two rounds of complete census data from all adult villagers in the three participating villages enabled difference-in-difference and descriptive geographical analyses of the activity's consequences, which we complemented with qualitative material from field notes and cognitive interviews.

As we assessed the outcomes of a public engagement activity without an explicit behaviour change objective, a perhaps obvious rebuke is that behaviour change theory and interventions are more targeted and therefore more likely to produce "desirable" consequences for antibiotic-related health behaviour (for an overview of behaviour change approaches in AMR, see e.g. Batura et al., 2018). This may indeed be the case, but our study contributes nonetheless to the understanding AMR awareness raising, for three main reasons:

1. Our public engagement activity was developed based on previous qualitative research in Southeast Asia that highlighted the mismatch between local conceptions of illness and medicine on the one hand, and biomedical language and concepts around antibiotics and pathogens on the other hand. This would suggest that our translational effort may make antibiotic-related content more accessible for the local rural population than context-insensitive material.

2. Our social research study does not follow public health behaviour change theory, but this does not imply that our approach is a-theoretical. Our conceptual framework is grounded in the literature on public engagement with science and related anthropological and sociological AMR literature. We thereby consider two main pathways linking the public engagement activity to people's attitudes and behaviours, namely content and social networks, which are subject to contextual variation (see the section "Background" for details).

3. We argue that any kind of health communication can entail intended as well as unintended outcomes (Cho and Salmon, 2007), and the recognition of contextual variation applies to small-scale public engagement activities, as well as to mass communication campaigns and evidence-based medicine more broadly (Pearce et al., 2015).

Considering that 125 countries have begun implementing AMR awareness campaigns (WHO et al., 2018), the outcomes documented in our study are important to inform future assessments of other AMR-related communication activities. More specifically, our research documented that, although participants tended to interpret the content of the activity in general rather than antibiotic-specific terms, our translational effort was associated with a mild alignment between people's antibioticrelated attitudes and treatment choices and the messages of the WHO. Yet, if participants made sense of the new information, this also resulted in at least one case in the confidence to start selling antibiotics and increasing the informal supply of medicine. Indirect exposure to the activity through conversations and posters had yet more varied consequences within and across our three case study villages. Within the villages, ongoing re- 
interpretation rendered the messages partly contradictory and unactionable. Across the three sites, confounding factors like road construction and parallel public health programmes interacted with the activity (as they would in real-life large-scale AMR communication activities), creating a dynamic healthcare supplyand-demand environment and fuelling rumours about the activity. In addition, village-specific patterns of illiteracy contributed to different levels of indirect exposure. Variations of village social network structures stemming possibly from seasonal change or the longer-term presence of the research team (rather than the activity per se) might have similar if not more pronounced effects on aligning health behaviours with WHO positions. Taken together, our study contributes to the knowledge of AMR communication and more broadly to the field of public engagement with science, offering evidence on the intended and unintended consequences of sharing antibiotic-related information, on the influence of contextual factors on the distribution of these outcomes, and the problematic primacy of awareness campaigns in global AMR policy.

In the remainder of this paper, the section "Related literature" reviews the related literature on public engagement with science and sociological and anthropological studies of AMR. The review was the basis for the conceptual framework underlying our analysis (section "Conceptual framework"), wherein we considered a content and a social network pathway linking the educational activity and its outcomes. Details on the implementation case study are presented in the section "Methods", where the sub-section "The public engagement activity" focuses on the development of the educational activity, describes the diversity of the selected case study villages and the associated confounding factors, and reviews the implementation of the activity in these field sites. The remainder of the section "Methods" describes the study methodology, highlighting the mixedmethods triangulation design that used survey data alongside qualitative material from interviews and field notes. The section "Results" presents the results of the study, structured according to the research questions into overarching outcomes (section "Research question 1: overarching outcomes") and contextual factors contributing to the variation of the outcomes (section "Research question 2: contextual variation"). The section "Discussion" interprets the results and their practical relevance in light of the conceptual framework, considering study limitations like social desirability, research design effects, and external validity. We conclude in the section "Conclusion" that public engagement activities like ours require extensive evaluation to assess their consequences, that AMR communication activities should consider mandatory two-directional knowledge exchange components, and that we should question the current salience of the awareness-raising and behaviour change agenda in global AMR policies.

\section{Background}

Related literature. This study is an example of public engagement as a form of AMR-related communication, which currently inhabits a dominant position in AMR policies to address the popular use of antimicrobials. This section situates our study in the literature on public engagement with science and related anthropological and sociological literature on AMR.

According to Stilgoe et al. (2014, p. 5), the broader practice of public engagement as science communication has evolved "from deficit to dialogue" - an evolution that over past decades has replaced the approach of public "education" and "understanding" with the idea of "public engagement" (Leshner, 2003; Retzbach and Maier, 2014). The broad variety of public engagement activities globally includes, for instance, infographics, science cafés, festivals, showcasing events, village drama, or theatre plays (Dalrymple, 2006; Etherton and Prentki, 2006; Skinner et al., 1991; Stilgoe et al., 2014). Such activities can have creative and collaborative elements, for example where theatre groups work with funders or are involved in conveying health-related messages (Haddon, 2006; Etherton and Prentki, 2006; Lafrenière and Cox, 2013).

The public engagement with the sciences in general and the medical sciences and global health in particular has been receiving growing attention among researchers and research funders (Cohen et al., 2008; Hamlyn et al., 2015; Research Councils UK, 2011; Wilson et al., 2014). Engagement activities are now understood as a way to broaden the appreciation and impact of research, but they can also involve bidirectional communication with the target groups and users of the research or be an instrumental means for "community mobilisation" and health behaviour change (Lafrenière and Cox, 2013; Kilroy et al., 2007). In practice, health-related public engagement is often instrumental and mirrors the persistent "deficit model" of science communication that was associated with the earlier phases of public education and understanding (Suldovsky, 2016; Meyer, 2016; Cortassa, 2016). While some observers argue that healthrelated public engagement has been undergoing a cultural change in line with changing patient-physician relationships in highincome countries (Ko, 2016), health-related public engagement typically involves health education and awareness raising, behaviour change communication, or "community mobilisation" for health interventions and public health research (Roh et al., 2018; Nyirenda et al., 2018; Lim et al., 2016; Davis et al., 2017).

In the specific area of AMR, aside from public health measures to reduce infections, recommended global actions targeting antimicrobial use among the general population are limited to education and awareness raising (The Review on Antimicrobial Resistance, 2016, pp. 19-20; Gelband et al., 2015; Department of Health, 2013; WHO, 2015). The framing of these activities typically alludes to apocalypse and crisis, and evokes military metaphors on the "war against superbugs" (Nerlich and James, 2009; Davis et al., 2017); the activities themselves are regularly conceptualised as public engagement in line with the deficit model approach to engagement (Howard et al., 2013; Roh et al., 2018; Allison et al., 2017). Yet, as a form of science communication, AMR education and awareness raising faces formidable challenges.

Davis et al. (2017) outlined the complexities of mass-media communication of AMR, involving the co-production of knowledge through overlapping channels of communication, potentially contradictory messages, and the attribution of blame by scientists and media to the "lay public."” Lambert (2016, paragraph 8) argued in a similar vein and cautioned that the universal approach to AMR communication "disregards the fundamental requirement for strategies to be context-appropriate if they are to be effective," which can entail potentially harmful misinterpretations that could "lead people who genuinely need antibiotics to avoid or refuse them." Language is a channel through which such adverse reactions can materialise, which does not only relate to terminology and concepts to communicate AMR (Mendelson et al., 2017; Simba et al., 2016), but also interpretative processes that can entail for instance a "backfire effect" of reinforcing a myth by trying to debunk it (Peter and Koch, 2016). At the same time, the deficit logic of AMR communication typecasts the public explicitly as "unaware" of AMR and implicitly as "ignorant." Qualitative research has broken up the stereotype of the medical ignoramus, shedding for example light on arguments surrounding vaccine refusal that can be interpreted as consistent with postmodern worldviews, concerns of control over the body, and challenges of epistemic legitimacy (Carrion, 2018). 
Science communication (like many processes and interventions in international development) has also been argued to suffer from reproducing inequalities, as both the production and reception of the communication may put already marginalised groups at a systematic disadvantage (Dawson, 2018). The relationship between existing and new inequalities thereby suggests that target group heterogeneity and contextual factors can shape the outcomes of public engagement (Bull et al., 2010). Based on the public engagement with science literature, our premise is therefore that any AMR communication activity is prone to yielding heterogeneous and potentially problematic interpretations among the target population; to colliding with the conceptions, concerns, experiences, and realities of the target populations; and to reproducing existing social gradients.

Conceptual framework. We encapsulated these expectations in the conceptual framework that guided the analysis of our research questions. Depicted in Fig. 1, the framework linked the activity to health-related attitudes and behaviours, mediated by contextual factors. We hypothesised two main pathways of impact.

First, the content pathway (yellow-shaded upper pathway) in Fig. 1 hypothesised that attitudes and behaviours might be affected by the content of the activity, conveyed via direct participation and indirect exposure from posters and conversations (see the section "The public engagement activity" on the different types of exposure). Processes of translation and interpretation would determine whether and for whom the content is conceivable. These processes would not only be subject to language barriers but also to different and potentially irreconcilable conceptions of medicine and illness across cultural boundaries, both of which may make it difficult to relate to the content of the activity. Yet, even if people could make sense of the information, any effect would still depend on the physical and health system landscape, which might render the information useless or "inapplicable"-for example, if antibiotic access through trained and formal healthcare providers was simply unattainable. If the information could be related to and acted on, however, there is no guarantee that attitudes and behaviours would automatically align with the messages of the WHO, owing to which we did not hypothesise a particular direction of the effect.

Second, we hypothesised that the educational activity could also influence treatment-seeking behaviour irrespective of content, through a social network pathway (orange-shaded lower pathway in Fig. 1). Our presence in the case study villages involved one-week surveys followed by the half-day activity in which villagers reflected as a group on illness and medicine. As a social event, the educational activity might thereby have affected social network structures in two ways: on the one hand, the activity might have created or strengthened the social network among the participants irrespective of its content (similar to the expectations of participatory approaches, see e.g. Arnold and Fernandez-Gimenez, 2007; Park, 1999). On the other hand, other villagers might deem the participants more "knowledgeable" and therefore approach them more often for help during illnesses (similar observations have been made in public engagement activities reported in Bull et al. 2008). Considering that health behaviour does not take place in isolation (Peglidou, 2010), either case might influence healthcare choices through stronger support networks. ${ }^{4}$

In sum, we hypothesised that two main pathways link the educational activity to effects on health-related attitudes and behaviours, subject to contextual complications like ongoing and ungoverned translation and re-interpretation of information, uneven physical and health system landscapes, and changing social network structures that could contribute to heterogeneous and potentially inequitable outcomes. Research Question 1 thereby considered the overarching effect of the educational activity (both pathways combined), whereas Research Question 2 examined each of the three outlined contextual factors in greater detail.

\section{Methods}

The public engagement activity

Development and design. The educational activity was part of the public engagement portfolio of a social survey on antibiotics, medicine, and treatment-seeking behaviour in Chiang Rai, Thailand, and Salavan, Lao PDR (Haenssgen et al. 2018b).

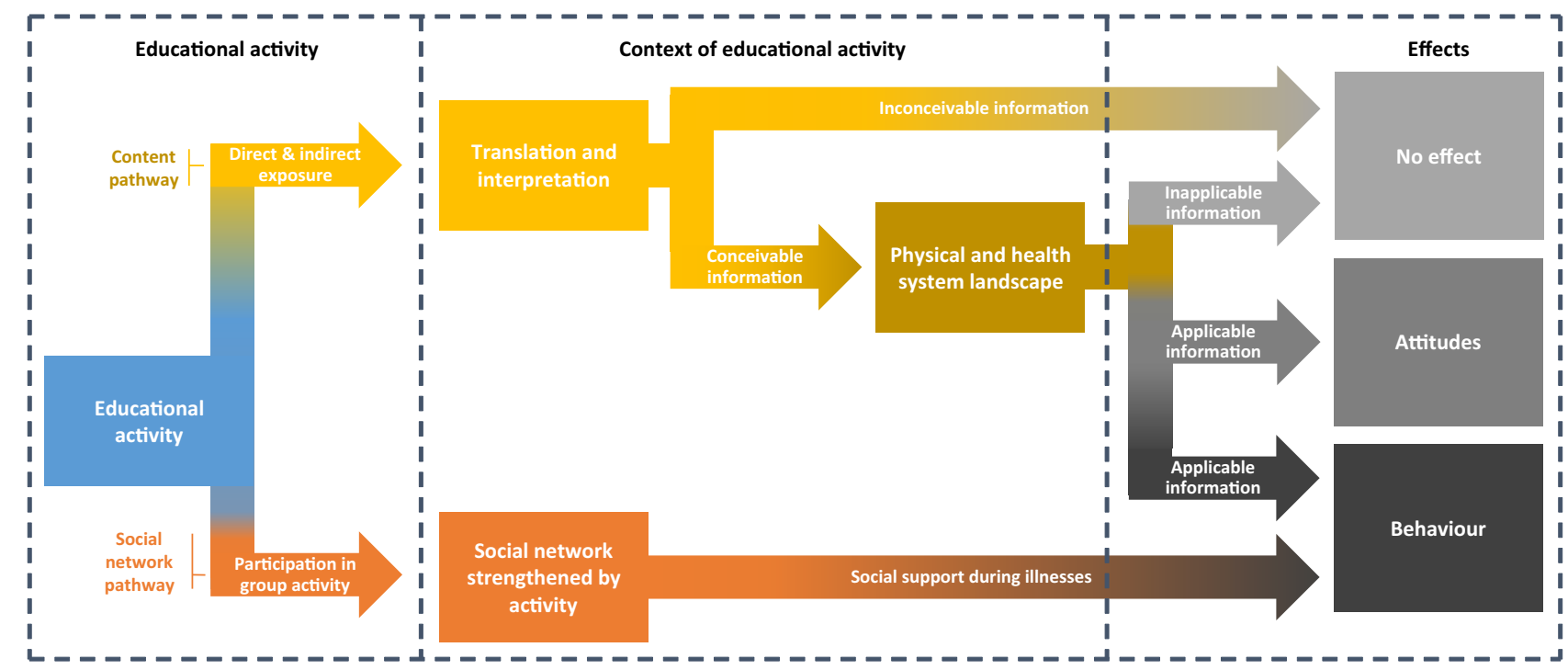

Fig. 1 Conceptual framework, linking the educational activity to effects on antibiotic-related attitudes and behaviour, mediated by contextual factors. The upper content pathway (yellow) hypothesises that direct (participation) and indirect exposure (posters, conversations in village about the activity) can affect people's attitudes and behaviours, mediated by the translation and reinterpretation of the activity content, and by the physical and health system landscape, which can render the information inconceivable and inapplicable. The lower social network pathway (orange) hypothesises that the activity fosters social networks irrespective of its content, which could affect people's treatment-seeking behaviour 
The design of the activity responded to our previous research in Southeast Asia with "translating AMR" as a conceptual starting point. On the one hand, the activity aimed at sharing some ideas about antibiotics and drug resistance. Using local media and local language, we did not only translate the medical language into popular terms, but "translating AMR" also meant harmonising the language with local conceptions of illness. On the other hand, the activity was meant to be a learning opportunity for our team to gain insights into the local context of medicine and healing, and to understand how our messages were received.

The educational activity was developed by a team of four Southeast Asian social scientists. Two of the researchers-Thai and Burmese, with experience in public engagement with science and youth development and leadership-were directly involved in preceding qualitative AMR research in Southeast Asia. This research laid the foundation for the current study, involving qualitative development studies research with fever patients in rural Chiang Rai and Yangon (Myanmar) and problematising the disjunction between technical and global biomedical language and local conceptions of antibiotics (Haenssgen et al. 2018a; Khine Zaw et al. 2018). The other two researchers-Thai and Lao, with experience in development studies and youth development and leadership - contributed their expertise in rural development and community-based activities in northern Thailand and southern Lao PDR. This range of backgrounds enabled the team to translate WHO messages into content and media more accessible to the rural population in Chiang Rai and Salavan. More specifically, we considered the following messages from the Campaign Toolkit for the WHO World Antibiotic Awareness Week 2016:

- "only use antibiotics when prescribed by a certified health professional,"

- "never demand antibiotics if your health worker says you don't need them,"

- "always follow your health worker's advice when using antibiotics," and

- "never share or use leftover antibiotics" (WHO, 2016, p. 6).

A major complication of these messages in our field sites was that people were often unfamiliar with the technical term "antibiotic" (Tangcharoensathien et al., 2018), people might not realise which medicines have antibiotic ingredients (e.g. Mybacin Lozenges cough drops, containing $2.5 \mathrm{mg}$ neomycin), and vernacular notions like "germ killer" in Thailand may not be congruent with biomedical definitions of antibiotics (including e.g. anthelmintic and antifungals). In addition, WHO awarenessraising material commonly includes notions of drug-resistant bacteria and that antibiotics should not be used for viral infections, but our previous research indicated that distinctions between bacteria and viruses as disease-causing agents were uncommon in our sites. Our translations and adaptations therefore involved references to antibiotics through pictures and the popular and fairly unambiguous interpretation as "antiinflammatory medicine" (which also alludes to ideas of illness as "inflammation" of the body), references to generic "germs" that evolve in response to specific types of medicine, the health implications when these germs spread, and narrated and sung stories that featured ill villagers and their treatment choices in the local context. We field-tested the educational activity in two villages in Chiang Rai. Following extensive feedback sessions with volunteer facilitators from the School of Social Innovation at Mae Fah Luang University in Chiang Rai, we shortened the length of the activity, included ice-breaking activities, and made the role of the volunteers as moderators rather than educators more explicit.

The ensuing product was a half-day activity in which the research team (six to eight volunteers) and the villagers (20-35 adult participants from across the village) got to play the roles of message sender and receiver equally. The list of sessions (including expected outcomes, incorporated message, and direction of communication) is detailed in Table 1 , all of which were delivered in central Thai. ${ }^{5}$ The first of the six sessions was a mapping activity to learn about the local healthcare landscape, treatment-seeking behaviours, and the social networks involved in villagers' treatment-seeking processes. Secondly, a medicine sorting game helped us understand local categories of medicine and their purpose, while also suggesting to the participants that antibiotics should not be bought over the counter. Thirdly, a "resistance" game introduced the participants to the idea that germs can become stronger if they are not treated correctly. Following a short break, the fourth and fifth sessions comprised the adaptation of a traditional pop song ${ }^{6}$ and a narrative about a "sick village" and a "healthy village" as familiar channels of communication. The last activity_poster making-allowed us to see how the participants understood and interpreted the content to which they were exposed during the activity. At the end of the poster-making session, participants would present and explain their work to all attendees, and the moderators would discuss and edit the content on the spot in case of potentially detrimental interpretations like "medicines are dangerous" or "you need a prescription for any medicine [incl. paracetamol]" (which could scare people off life-saving medicine or overburden healthcare providers, see Lambert, 2016; the section "Implementation process" provides actual examples of the edited posters). The edited posters would subsequently be displayed at shops, community halls, and schools in the village as a means of communicating between the activity participants and the remaining villagers.

Field sites. We implemented the activity in three villages in northern Thailand (Chiang Rai; see map in Fig. 2), which serve as our case study in this paper. Although low-income and middleincome countries in Southeast Asia have been described as a hotbed for AMR (Chereau et al., 2017), Thailand has increasingly been treated as a regional example of successful antimicrobial stewardship, whose extensive national policies and local initiatives have made it a country with one of the lowest antibiotic prescription rates in the region (Tangcharoensathien et al., 2017; WHO SEARO, 2016; Holloway et al., 2017, p. 11). For example, bans on informal antibiotic sales have been introduced (and increasingly enforced) in Chiang Rai province, the government has been conducting long-term antibiotic stewardship and public education programmes, and public health facilities themselves have initiated small-scale education campaigns that target their clients and rural populations. Yet, extensive private healthcare provision and persistent access to medicine through informal channels (e.g. grocery stores, retired doctors) have also catered to a continuing demand for pharmaceuticals (incl. antibiotics) as an established form of "good care" (Sringernyuang, 2000, p. 37, p. 80; Chuengsatiansup et al., 2000, pp. 8-9, pp. 28-29). For example, a recent study in Chiang Rai district found that $46.9 \%$ out of 84,000 public primary care patients with acute infections in 2015 and 2016 received an antibiotic, which the authors deemed "likely to represent [...] overuse" (esp. for pharyngitis; Greer et al., 2018, p. 8).

The three case study villages represented the diversity of rural Chiang Rai (peri-urban vs. remote vs. ethnically diverse), which we selected purposively with local partners from Mae Fah Luang 


\section{Table 1 Description of educational activity}

\begin{tabular}{|c|c|c|c|c|c|}
\hline Session & $\begin{array}{l}\text { Duration } \\
\text { (min) }\end{array}$ & Description & Expected outcomes & Main message $^{a}$ & $\begin{array}{l}\text { Direction of } \\
\text { communication }\end{array}$ \\
\hline Ice breaking & 15 & & Ice breaking & & \\
\hline $\begin{array}{l}\text { (1) Community } \\
\text { mapping }\end{array}$ & 30 & $\begin{array}{l}\text { In groups, participants sketch a village map and } \\
\text { mark down their own houses, important } \\
\text { locations in the village, and draw lines to } \\
\text { connect themselves with places, as well as } \\
\text { people they go to when sick }\end{array}$ & $\begin{array}{l}\text { Team learns about places, existing } \\
\text { health networks, and health facilities } \\
\text { within and nearby the village }\end{array}$ & & $\begin{array}{l}\text { Participants } \\
\downarrow \\
\text { Team }\end{array}$ \\
\hline \multirow[t]{3}{*}{$\begin{array}{l}\text { (2) Medicine } \\
\text { sorting }\end{array}$} & 30 & $\begin{array}{l}\text { Part (I) Participants sort medicines into two } \\
\text { groups: those that they know and do not know }\end{array}$ & $\begin{array}{l}\text { Team gains overview of medicines and } \\
\text { their purposes from participants' } \\
\text { perspective }\end{array}$ & & $\begin{array}{l}\text { Participants } \\
\downarrow \\
\text { Team }\end{array}$ \\
\hline & & $\begin{array}{l}\text { Part (II) Participants free-sort pictures of } \\
\text { common medicines into their own categories }\end{array}$ & $\begin{array}{l}\text { Team understands participants' general } \\
\text { conceptions around medicines and } \\
\text { treatments }\end{array}$ & & $\begin{array}{l}\text { Participants } \\
\downarrow \\
\text { Team }\end{array}$ \\
\hline & & $\begin{array}{l}\text { Part (III) Participants sort medicines into two } \\
\text { groups: over-the-counter medicines and } \\
\text { prescription medicines }\end{array}$ & $\begin{array}{l}\text { Participants understand that there are } \\
\text { two ways to access medicines }\end{array}$ & $\begin{array}{l}\text { Only use antibiotics when } \\
\text { prescribed by a certified } \\
\text { health professional }\end{array}$ & $\begin{array}{l}\text { Team } \\
\downarrow \\
\text { Participants }\end{array}$ \\
\hline (3) Resistance & 30 & $\begin{array}{l}\text { Participants pass a germ around in a circle. } \\
\text { When music stops, person with the germ } \\
\text { answers a right-or-wrong question about taking } \\
\text { medicines. If incorrect, they are out of the game, } \\
\text { the germ evolves, and the game continues. The } \\
\text { last remaining person wins a prize. }\end{array}$ & $\begin{array}{l}\text { Participants become familiar with the } \\
\text { idea of bacteria evolving and resisting } \\
\text { medicines }\end{array}$ & $\begin{array}{l}\text { (1) Germs can become } \\
\text { "stronger" if treated } \\
\text { inappropriately until the point } \\
\text { that there is no medicine to } \\
\text { treat them anymore } \\
\text { (2) Drug resistance can } \\
\text { spread }\end{array}$ & $\begin{array}{l}\text { Team } \\
\downarrow \\
\text { Participants }\end{array}$ \\
\hline Break & 15 & & Break & & \\
\hline (4) Song & 10 & $\begin{array}{l}\text { Traditional pop music played and sung by team, } \\
\text { with adjusted lyrics relating to seeking advice } \\
\text { from health professionals when sick. After a few } \\
\text { rounds, participants are invited to sing and } \\
\text { dance together. }\end{array}$ & $\begin{array}{l}\text { Participants do not underestimate the } \\
\text { importance of seeking professional } \\
\text { help }\end{array}$ & $\begin{array}{l}\text { "Seeing the doctor" is the best } \\
\text { way to assess your medical } \\
\text { needs }\end{array}$ & $\begin{array}{l}\text { Team } \\
\downarrow \\
\text { Participants }\end{array}$ \\
\hline (5) Roleplay & 20 & $\begin{array}{l}\text { A short skit performed by team with a simple } \\
\text { storyline around antibiotics and antibiotic } \\
\text { resistance }\end{array}$ & $\begin{array}{l}\text { Participants gain a deeper } \\
\text { understanding about drug resistance } \\
\text { and realise their own parts in the issue }\end{array}$ & $\begin{array}{l}\text { (1) Always follow health } \\
\text { worker's advice when using } \\
\text { antibiotics } \\
\text { (2) Never demand antibiotics } \\
\text { if the health worker says you } \\
\text { don't need them } \\
\text { (3) Drug resistance can } \\
\text { spread }\end{array}$ & $\begin{array}{l}\text { Team } \\
\downarrow \\
\text { Participants }\end{array}$ \\
\hline (6) Poster & 30 & $\begin{array}{l}\text { Participants produce creative posters under the } \\
\text { title "What would you tell other people about } \\
\text { the activity today?" with help from team with } \\
\text { writing and screening the messages }\end{array}$ & $\begin{array}{l}\text { Team is able to visualise participants' } \\
\text { interpretation of its communication } \\
\text { and appreciate the nature of public } \\
\text { engagement activities in rural areas }\end{array}$ & & $\begin{array}{l}\text { Village } \\
\uparrow \\
\text { Participants } \\
\downarrow \\
\text { Team }\end{array}$ \\
\hline
\end{tabular}

University. Implementing our educational activity in these diverse settings was not only a challenge, considering village accessibility and our uniform implementation of the educational activity. The village-specific context was also an opportunity to learn how the diverse social, economic, and geographic confounders may interact with and influence the delivery and reception of AMR communication even within a single province.

The first village represented the peri-urban and industrialised facet of rural Chiang Rai. It was located in a special economic zone at the Thai-Lao border in Chiang Khong district. Residents of this village had received more formal education (5.3 years completed years of schooling on average) and were better-off in terms of wealth compared to the other two villages. ${ }^{8}$ They were also closer to mass media and health information sources and had a wider range of public, private, and informal healthcare options owing to their proximity to the district capital city, which could be reached within $10 \mathrm{~min}$ by car. Among the three villages, the Chiang Khong village was also most visibly involved in AMRrelated public health campaigns during the study period (longterm programmes also existed in the other two districts but tended to target health facilities rather than the general population). After we completed the first round of the survey and the educational activity, the district-level Public Health Office became stricter regarding sales of antibiotics in local shops. Village leaders were informed about these developments, but the looming threat of penalties led Chiang Khong shop owners to stop the sale of medicines almost altogether (including e.g. paracetamol, although it was not part of the policy). As we will explain in more detail in the section "Results", these salient health policy developments interacted with our educational activity, contributing to antagonism among villagers who felt that we were agents of the (misunderstood) public health intervention.

In contrast, the second village represented the living conditions of remote mountain villages in Chiang Rai. It was part of Chiang Rai district, situated in one of the poorest sub-districts in Thailand, and populated by the Thai-speaking Mien ethnic group. ${ }^{9}$ Access required a four-wheel-drive vehicle $(1.5 \mathrm{~h}$ from the nearest district capital), solar cells were the main source of electricity, and government policies had prevented the village from infrastructure investments because of its location in a national park. The village was isolated, owing to which visitors were rare and typically included non-governmental development workers and legal advocates (whose visits tended to be shorter and less extensive than our survey activities, making our team a rather prominent visitor). Contrary to our expectations, however, isolation did not mean that the village community was close-knit. Young villagers would not normally chat with older groups in the village, and villagers more generally would refrain from socialising outside their homes considering that no lighting was available in the solar-powered village after they returned from work.

The last village reflected the ethnic and social diversity of rural Chiang Rai through a clear geographic segmentation of its ethnic groups Lahu, Akha, and Thai. The village was located near the border area to Myanmar in Mae Fah Luang district, owing to which a small part of the population was also stateless. The village had only acquired paved road access one year prior to the survey, which enabled travel times of $45 \mathrm{~min}$ to the nearest town. Before having gained road access, villagers would only receive half-yearly visits from village health volunteers (who would otherwise 


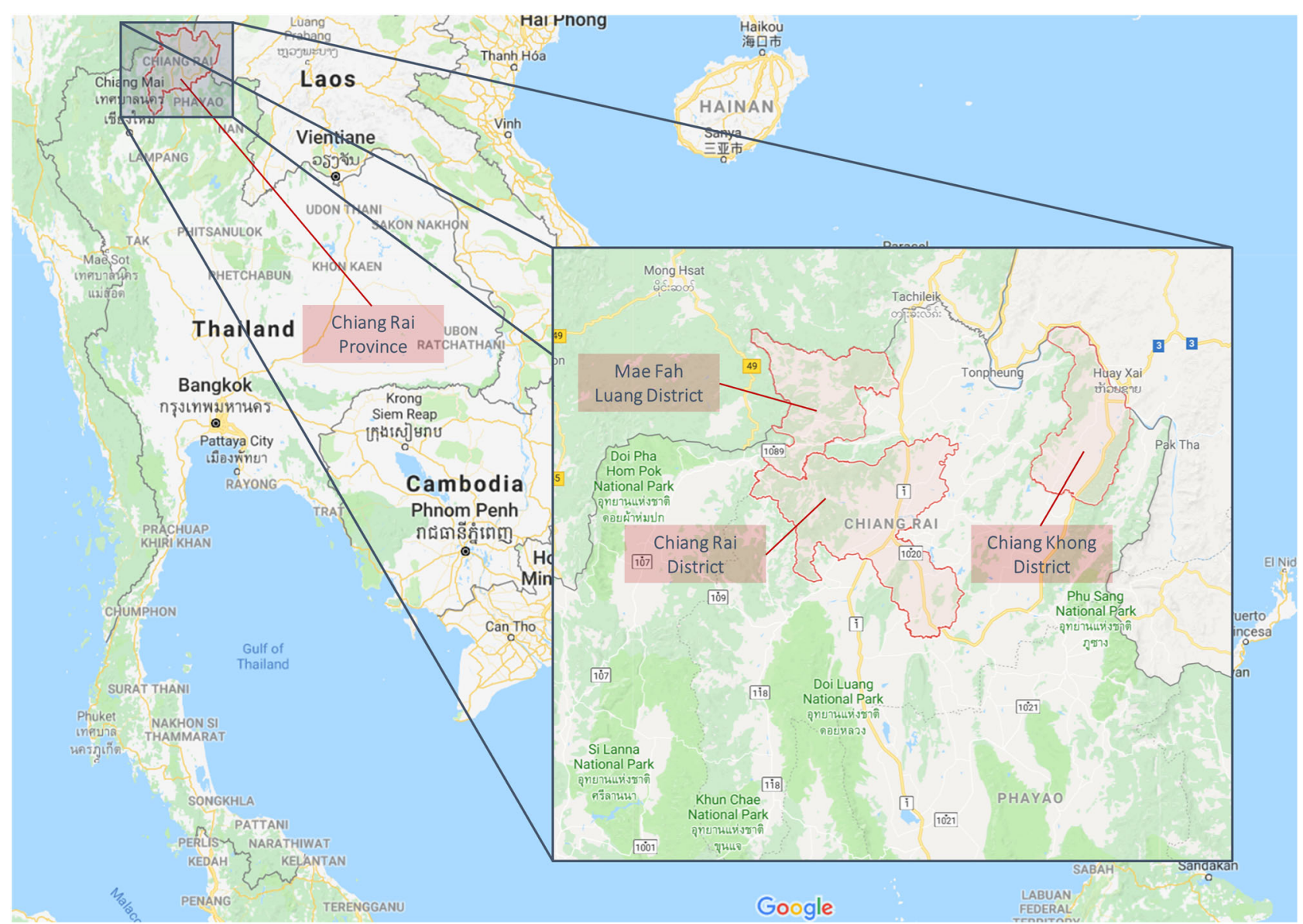

Fig. 2 Map of field sites in Chiang Rai province, northern Thailand. To reflect the diversity of the province, one village each was selected in the districts Chiang Khong (peri-urban, industrialised), Chiang Rai (poor, remote), and Mae Fah Luang (ethnically diverse, statelessness). Source: authors, adapted from Google Inc. (2017)

typically reside in villages) and report that it was common to die in the village or on the way to reaching formal healthcare facilities in the district capital. Further road construction-which was completed shortly after the educational activity-reduced travel times to the district town by another $15 \mathrm{~min}$ and thereby effectively increased healthcare supply parallel to our educational activity - at least for villagers with cars and motorcycles (note this does not imply that formal healthcare access was suddenly "easy"). Furthermore, social interactions within the village were often confined within the respective ethnic groups, who would typically stay among each other at ordinary village gatherings like village meetings or bonfires during the colder winter months.

We summarise some of these village idiosyncrasies graphically in Fig. 3. Row 1 displays the distribution of ethnic groups, Row 2 represents language ability, and Row 3 indicates antibiotic-related knowledge and attitudes prior to the activity (measured as the number of "desirable" answers out of four questions related to WHO AMR messages; see Table 4 in the section "Data ollection"). Among others, the figure illustrates the ethnic uniformity of the Chiang Rai village and clear geographic divisions between ethnic groups in Mae Fah Luang and Chiang Khong. The Chiang Khong village comprised almost exclusively Thai speakers (central and/or northern dialects), whereas people who did not speak Thai were more prevalent in the other two villages, especially in Mae Fah Luang (we describe in the following section and in the section "Translation, language barriers, and social exclusion" that non-Thai speakers were more likely to be excluded from the activity and from indirect exposure). Antibiotic knowledge and attitudes seemed to be distributed evenly, but Table 2 demonstrates that different ethnic groups exhibited systematically different responses (with mainstream Thai ethnicities not necessarily scoring highest). Further baseline data from the three villages will be presented in the "Results" section as part of the difference-in-difference analysis.

Implementation process. The educational activity was implemented at local village halls, and Fig. 4 contains impressions from the implementation. Between 20 and 35 adults participated in each village, who were recruited through contacts made during the first survey round and with the help of village leaders. For those 82 activity participants whom we later re-surveyed, Table 3 shows that they were on average younger and included a high share of women and Thai speakers than the population average (albeit Thai was not the mother tongue for more than half of the participants). However, the recruitment of the participants aimed at a diverse range of ethnic backgrounds from across the village. The result is depicted in Fig. 5, which visualises respondents who reported participating in the activity (i.e. direct exposure, blue dots), having talked about it (i.e. indirect exposure, light-green dots), having seen the posters (i.e. indirect exposure, yellow dots), or both of the latter (green dots). The figure demonstrates that the educational activity involved respondents from all geographical parts of the villages, and all major ethnic groups were involved in the activity. Although participants in Mae Fah Luang were clustered geographically in the Lahu segment of the village, indirect communication still exposed all village segments to the activity. 
a

b

Chiang Rai District

C

Mae Fah Luang District
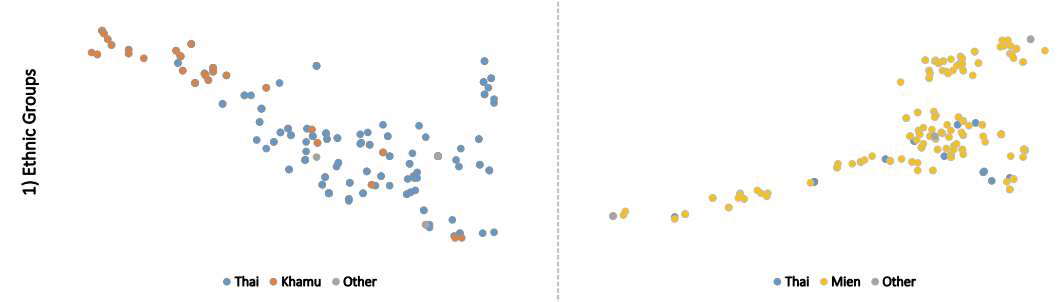

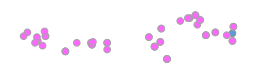

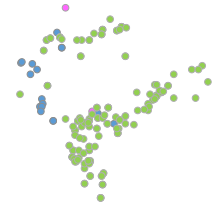

- Thai - Akha - Lahu

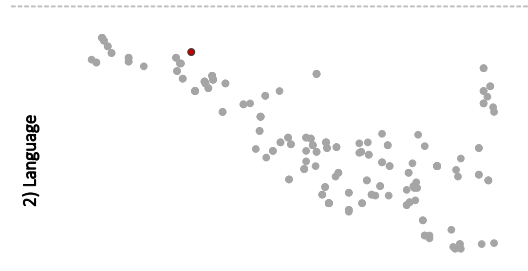

- Thai - Mien - Other
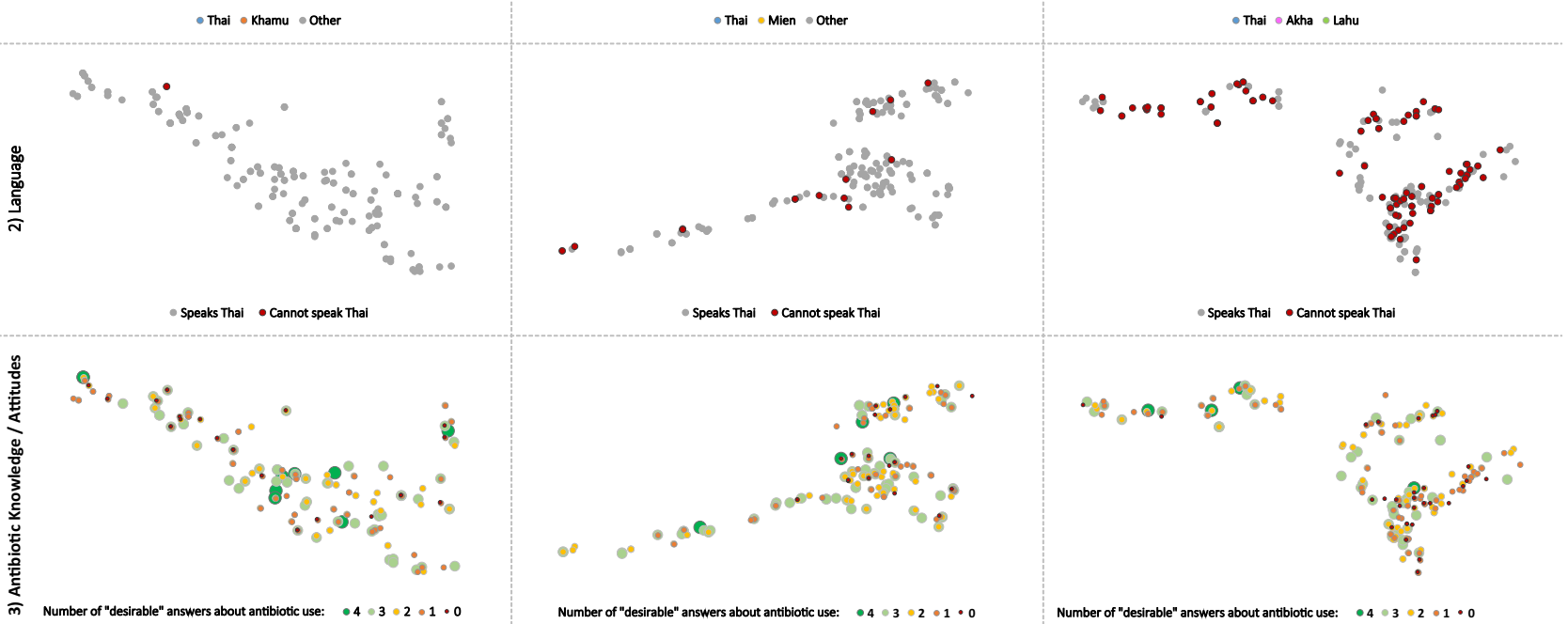

- Speaks Thai - Cannot speak Thai
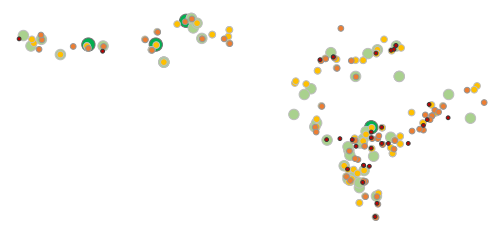

Fig. 3 Geographical representation of ethnic composition, language, and antibiotic knowledge in case study villages: Ethnic groups (1) were more clearly separated in the Chiang Khong a and Mae Fah Luang villages $\mathbf{c}$ than in the Chiang Rai village $\mathbf{b}$. Non-Thai speakers (2) were common and equally distributed in the Mae Fah Luang village $\mathbf{b}$. Antibiotic-related attitudes measured by the number of "desirable" answers to four attitude and knowledge questions (3) were spread relatively evenly across all three villages but low responses appeared to cluster in the Lahu segment of the Mae Fah Luang village c. Notes: "Baseline" (R.1) data, using full sample data. $n=204 \mathbf{a}, n=200 \mathbf{b}$ and $n=222$ c. Marker size adjusted to distinguish overlapping responses

Table 2 Antibiotic knowledge and attitude scores by ethnic group across survey villages

\begin{tabular}{|c|c|c|c|c|c|c|}
\hline Ethnic group & Mean (std. dev) & $n$ & Mean (std. dev) & $n$ & Mean (std. dev) & $n$ \\
\hline Thai/Mueang & $1.95(1.09)$ & 160 & $1.59(1.12)$ & 27 & $1.79(1.02)$ & 24 \\
\hline Lahu & & & & & $1.54(1.01)$ & 142 \\
\hline Mien & & & $2.01(0.99)$ & 170 & & \\
\hline Khamu & $1.59(1.00)$ & 41 & & & & \\
\hline
\end{tabular}

The delivery of the activity took place in what our team described as an engaging atmosphere. Compared to the survey interviews (see following sub-sections), the team described the interactions with the villagers as more open and uninhibited. This suggested that the villagers were less afraid of sharing ideas about medicine and well-being, which may be unsurprising considering that knowledge sharing took place in a group environment involving music and games rather than a conventional face-toface interview setting. This degree of openness enabled our team to learn about the village context beyond the qualitative and quantitative research data. For example, in the "Medicine Sorting" session, we learned that Mae Fah Luang villagers categorised medicine into "medicine for adults" and "medicine for children." The participants explained during this session that they would be extra careful with "medicine for children" and follow instructions closely, while they would buy "medicine for adults" for themselves over the counter. Antibiotics fell into both categories and would be treated differently thus. Examples like this impressed the team and helped them to contextualise the survey responses around the language and purposes of antibiotic use. $^{10}$

Despite the open atmosphere, and even though only Thai nonmedical volunteer facilitators participated in the delivery of the activity, villagers afterwards recalled that our team primarily "came in to teach" rather than being learners themselves. This indicated that our interaction was still perceived as onedirectional from the villagers' perspective, while our messages were less authoritative than medical staff's (whose role as educators would be more established). We also observed that interactions among the participants were mostly limited to existing groups in the villages, especially in the Chiang Rai village (young and old interacting among each other) and the Mae Fah 


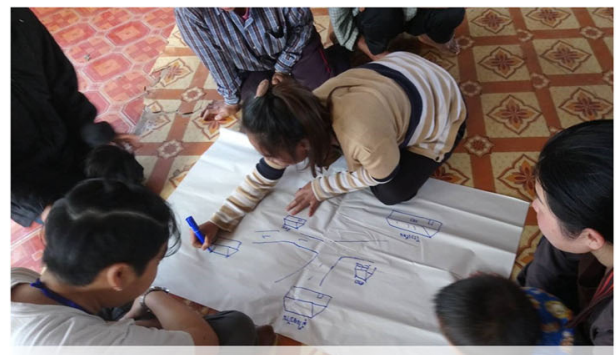

\section{Community Mapping}

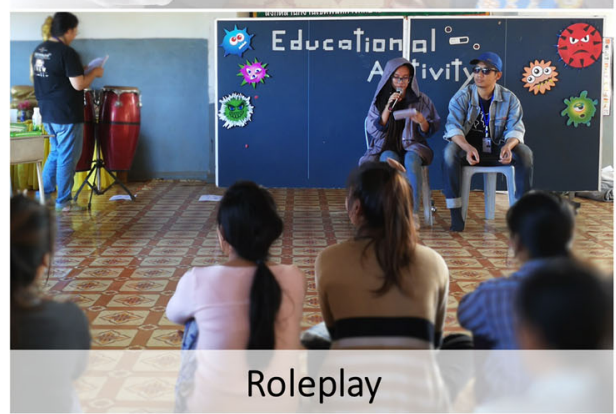

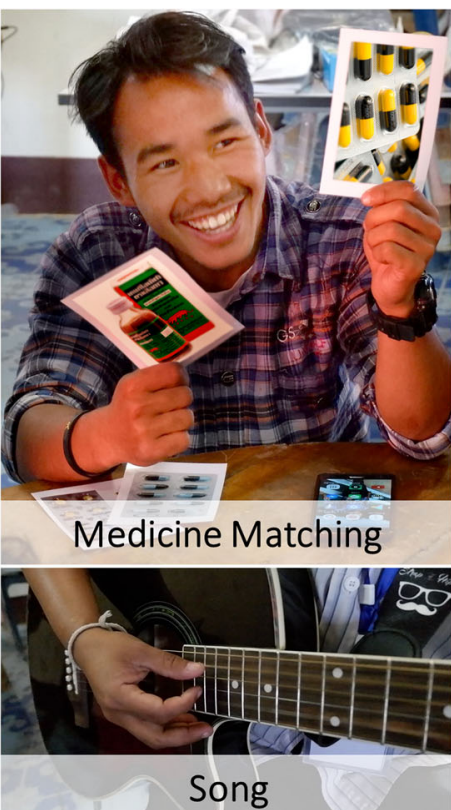

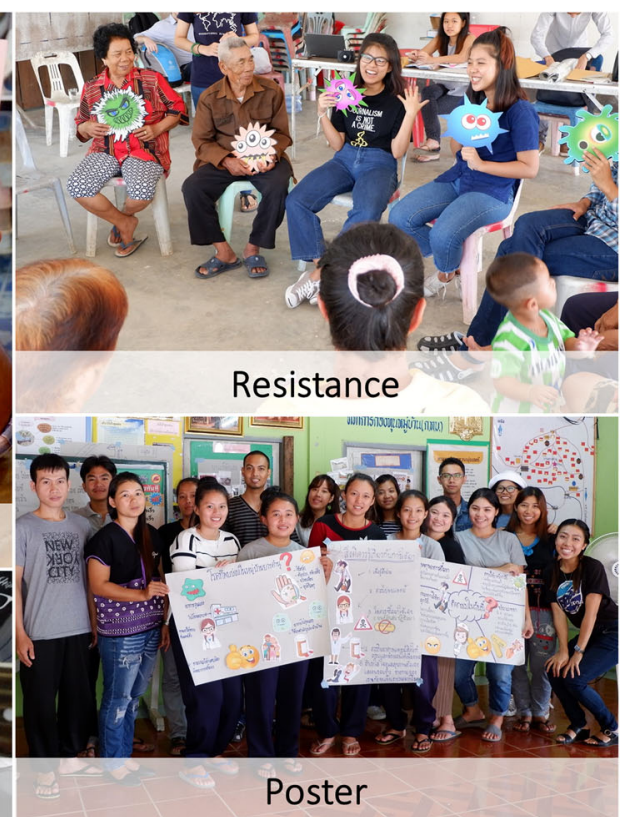

Fig. 4 Impressions of various sessions within the educational activity. Photographs include both trial runs and final implementation. Photo credits: Nutcha Charoenboon (community mapping, medicine matching, resistance, song, poster), Patchapoom U-thong (roleplay); reproduced with permission

\section{Table 3 Characteristics of individuals by participation in educational activity}

\begin{tabular}{|c|c|c|c|}
\hline Variable & $\begin{array}{l}\text { Did not participate } \\
(n=466) \\
\text { Mean (std. dev) }\end{array}$ & $\begin{array}{l}\text { Participated throughout } \\
(n=72) \\
\text { Mean (std. dev) }\end{array}$ & $\begin{array}{l}\text { Participated partly } \\
(n=10) \\
\text { Mean (std. dev) }\end{array}$ \\
\hline Sex (\% female) & $0.52(0.50)$ & $0.72(0.45)$ & $0.50(0.53)$ \\
\hline Age & $48.01(15.55)$ & $43.56(15.68)$ & $44.5(15.74)$ \\
\hline Education & $4.11(4.83)$ & $4.60(4.44)$ & $2.40(4.06)$ \\
\hline Wealth index (range: $0-1)^{a, b}$ & $0.57(0.12)$ & $0.56(0.10)$ & $0.47(0.09)$ \\
\hline \% speaking Thai & $0.80(0.40)$ & $0.99(0.12)$ & $0.70(0.48)$ \\
\hline Ethnic group: Thai/Mueang & $0.33(0.47)$ & $0.36(0.48)$ & $0.10(0.32)$ \\
\hline Ethnic group: Akha & $0.10(0.30)$ & $0.06(0.23)$ & $0.10(0.32)$ \\
\hline Ethnic group: Lahu & $0.23(0.42)$ & $0.21(0.41)$ & $0.70(0.48)$ \\
\hline Ethnic group: Mien & $0.27(0.45)$ & $0.22(0.42)$ & $0.10(0.32)$ \\
\hline Ethnic group: Khamu & $0.06(0.24)$ & $0.15(0.36)$ & $0.00(0.00)$ \\
\hline Ethnic group: Other & $0.00(0.07)$ & $0.00(0.00)$ & $0.00(0.00)$ \\
\hline
\end{tabular}

Luang village (ethnic groups interacting among each other). Further minor impediments were late-comers and playing children in the village halls who would divert attendees' attention away from the activity.

Our team's overall impression was that the messages were not delivered fully despite the half-day engagement with the participants. Especially the feedback mechanism through the final poster-making session revealed the limitations and drawbacks of the activity. Figure 6 exemplifies two posters with edits by the study team. The top example shows that the messages from the activity were fed back as, "You shouldn't take medicines that you have never seen before;" the bottom example shows how the content extended into more general topics of well-being, like exercise and nutrition. The potentially less "powerful" delivery of our message may therefore not have been altogether disadvantageous because it may have attenuated the gravity of possible misinterpretations of our messages.

The edited posters were subsequently displayed in prominent village locations (3-5 posters per village, shown at shops, village halls, and schools), but exposure varied across the villages. In Mae Fah Luang, the posters were hung up in the village hall where the activity took place but were removed prior to our second visit 3 months later. The posters in the Chiang Khong village were salient and talked about, but rather because they were rumoured to be part of a governmental public health campaign to ban all informal medicine sales, and some shops reported removing them to avoid trouble. Poster exposure was possibly more effective in the Chiang Rai village where local stores and a school displayed them, and villagers reported having seen them for an extended period.

Research design. We use a mixed-method triangulation design with a dominant quantitative component to explore the processes and mechanisms underlying the outcomes of AMR-related educational activities (Creswell et al., 2008). The activity was embedded in a large-scale rural survey research project in Thailand and Lao PDR, interspersing two rounds of village census 
a

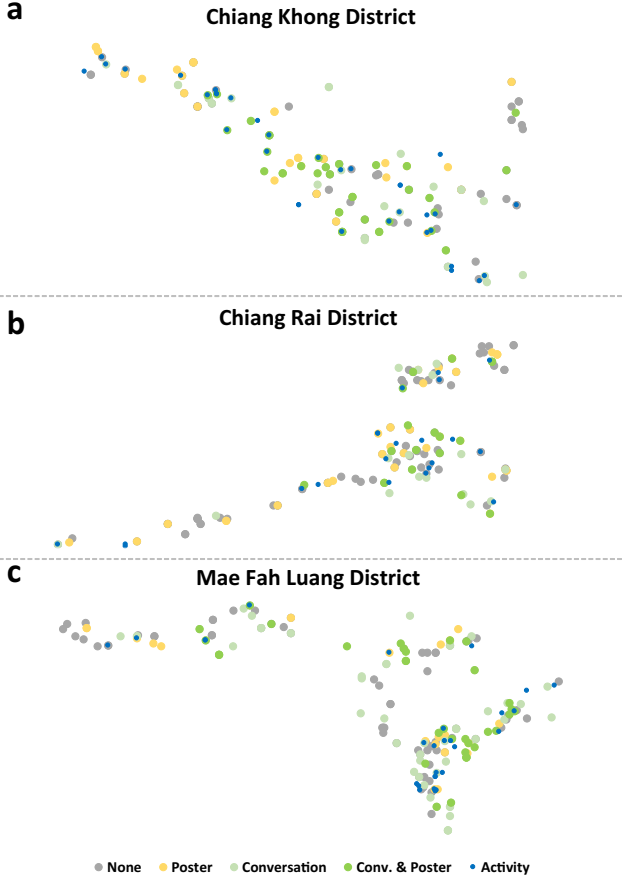

Fig. 5 Geographical overview of educational activity exposure across the case study villages: Unlike the Chiang Khong village $(\mathbf{a}, n=185)$ and the Chiang Rai village (b, $n=167$ ), participants of the activity in the Mae Fah Luang village (c, $n=196)$ were concentrated in one village segment (inhabited by the Lahu ethnic group). However, indirect exposure to the activity though conversations and poster display was spread evenly across all three villages. Notes: Exposure based on self-reported data whether respondents had participated in the activity, had talked about the activity, and/or had seen the activity posters. "Endline" (R.2) data, matched panel data. Marker size adjusted to distinguish overlapping responses

data collection (see Fig. 7 for a timeline of surveys and activity). The two rounds of complete census survey data for all adults in the three villages permitted us to trace changes in attitudes and behaviours among participants and non-participants of the educational activity, taking into account the complete social composition, relationships, and spatial distribution of the villages. The quantitative survey data thereby enabled difference-in-difference (i.e. before/after) analyses among directly and indirectly exposed participants, and non-participants as a "control group." Qualitative methods contextualised and validated the quasiexperimental quantitative analysis results. Note, however, that our assessment cannot legitimately claim the status of a formal impact evaluation, considering the obvious conflict of interest that an evaluation of our own project would entail.

The overall study was designed as an interdisciplinary project led by a social scientist and situated in the field of development studies with contributions from medical anthropology, economics, sociology, tropical medicine, and clinical research. It was designed to explore the role of marginalisation and knowledge in rural treatment seeking and antibiotic use, drawing on a framework that problematises behaviour at the interface between patients and the health system (Haenssgen et al. 2018b). The disciplinary orientation of the educational activity followed the direction of the project, namely social sciences (development studies) rather than medical sciences.

We obtained ethical clearance from the University of Oxford Tropical Research Ethics Committee (Ref. OxTREC 528-17) and the Mae Fah Luang University Research Ethics Committee on Human Research (Ref. REH 60099), and permission to access the study villages from the local government (from the provincial to the village level). Access to the villages was enabled through introductory letters from the sub-district authorities and personal introductions to the village leaders, the latter of whom would also announce the survey and the educational activity via the villages' public broadcasting system. People's participation in the survey and educational activity was voluntary, for which we obtained informed verbal consent, which was audio recorded and documented by the survey field investigators with a written record of oral consent for each participant. The participants received a small financial token of appreciation equivalent to GBP 1.00 for the survey and GBP 3.00 for the educational activity.

Data collection. The data to inform this study included survey data supplemented with cognitive interviews and observational data from the educational activity. The quantitative data represented a subset of the larger survey, covering complete censuses of adults in the three Chiang Rai villages where we carried out the AMR-themed educational activity. Within the selected villages, we approached all available households, enumerated their members, and interviewed all adults who provided (audio-recorded) informed consent.

Our survey instrument was a 45-min face-to-face questionnaire, collected electronically through tablets using the SurveyCTO software (Dobility Inc., 2017). The instrument captured location and demographic information of our respondents, individual and household characteristics, social networks, and healthcare provider preferences. We also evaluated the "desirability" of our respondents' attitudes and knowledge regarding antibiotic use, for which we presented them with images of common antibiotics (and recorded their knowledge thereof) and judged their answers to four attitude/ knowledge questions as described in Table 4. A further important feature of the questionnaire was the collection of sequential healthcare pathway data (Haenssgen and Ariana, 2017), from which we extracted information on healthcare choices, medicine use, and the activation of social networks during the course of acute illnesses or accidents that were resolved within the 2 months prior to the survey.

The study team developed the survey instrument in English, discussed the Thai meaning-based translation and its various interpretations, and subsequently piloted and revised the questionnaire with the help of cognitive interviewing (Willis, 2005). Involving several techniques like "thinking aloud" and explanations of the local interpretation of concepts, cognitive interviews enabled insights into how respondents understand and answer selected survey questions. Yet, we experienced that the "communicative norms from the English language and Western cultures" embedded in the cognitive interview method clashed with the communication style of our respondents (Park et al., 2014, p. 643), owing to which we dropped the "thinking aloud" components from the interviews. The local adaptation of the cognitive interview method nevertheless enabled a refinement of the survey instrument (e.g. in terms of questionnaire structure, question order, and the range of answer categories) ${ }^{11}$ The scope of the ensuing qualitative data also enabled us to triangulate and contextualise the quantitative survey results, for instance by prompting an examination of informal medicine sources and their composition in the case study villages and by shedding light on village living conditions beyond the information in the questionnaire. Regular survey team meetings during the survey and observations during the educational activity provided further contextualising information.

Overall, we surveyed 626 adults in the three villages during the first survey round and 637 during the second, the characteristics of whom are summarised in Table 5. Panel attrition was $12.5 \%$, 


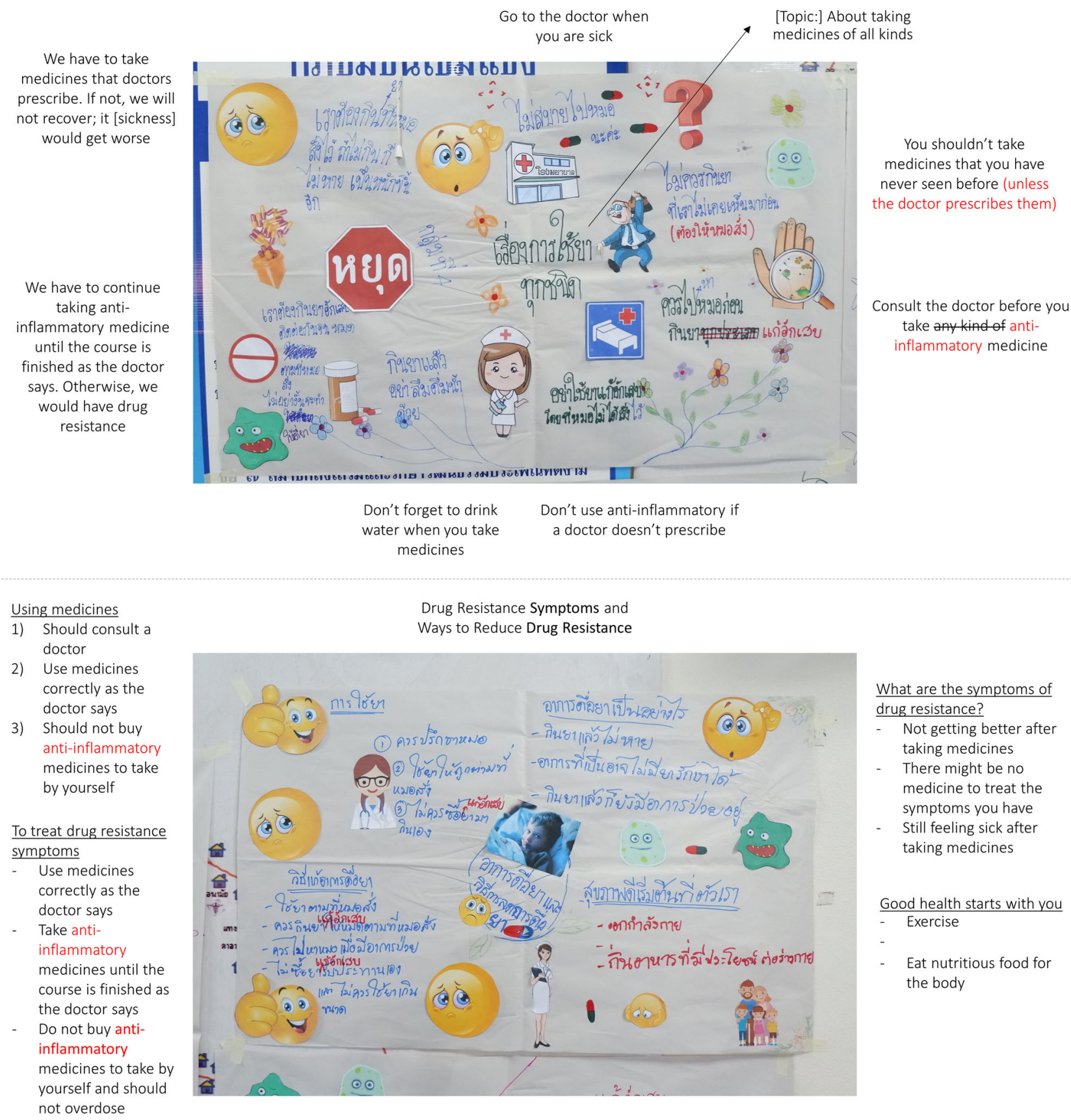

Fig. 6 Examples of posters produced by participants of educational activity: The top example shows that the messages from the activity were fed back as, "You shouldn't take medicines that you have never seen before;" the bottom example shows how the content extended into more general topics of wellbeing like exercise and nutrition. Notes: English text in red indicates edits by the study team on the poster. "Anti-inflammatory" medicine refers to the colloquial notion of antibiotics in Thailand. Source: activity participants. Photo credit: Nutcha Charoenboon; reproduced with permission

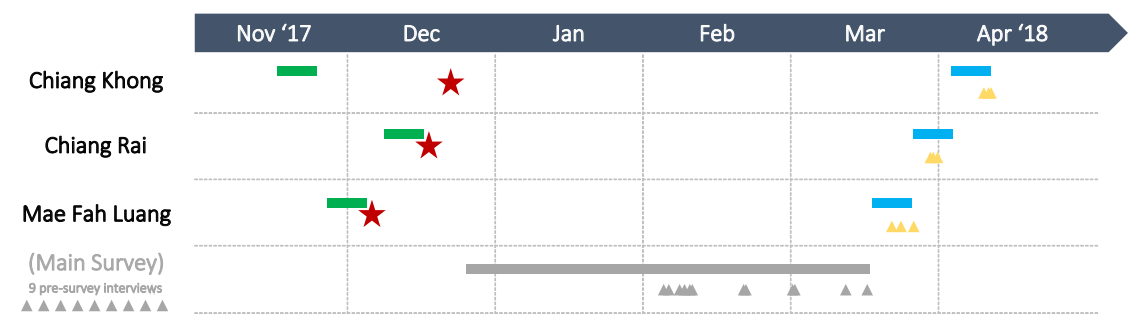

Key: $=$ Survey Round 1 (R.1) $\quad \star$ Educational Activity $\quad$ Survey Round 2 (R.2) $\Delta$ Cognitive Interview

Fig. 7 Timeline of surveys and educational activity. Second-round surveys took place approximately 3 months after each educational activity. Note: Logistical factors led to delays between survey round R.1 and activity in Chiang Khong village 


\section{Table 4 Sample responses to guide evaluation of survey answers to antibiotic questions}

\section{Questionnaire item}

16.4 Is there any situation for which you would buy this medicine?

16.5 Do you prefer other remedies such as herbs or cough syrup to this medicine for a sore throat?

16.6 If you were prescribed this medicine by a doctor and did not finish the course, would you keep it for future use?

16.9 Can your drug resistance ("due yah") spread to other people, for example if you sneeze on them?

\section{"Desirable" answer}

Respondent would not buy this medicine without a prescription from a doctor. No, I don't buy those.

Only if the doctor says that I should. Why would I buy it?

If presented with a choice, the respondent would choose alternatives before using antibiotics.

I try to avoid using these chemicals.

I treat sore throats with herbal medicine

first.

I take sponge baths before deciding whether I should take medicine.

Respondent would not store this medicine at home or share it with other people.

I do whatever the doctor says.

No, you must not do that!

I am afraid of having medicines at home.

Respondent appreciates explicitly or implicitly that drug resistance can spread. Not necessarily-depends on the illness really.

Yeah, it's scary.
"Undesirable" answer

Considers buying (or has bought) this medicine for self-treatment without a prescription.

Yes, you can buy it in the shop over there!

I haven't bought it, but why not?

Only for a sore throat, not otherwise.

The respondent would intuitively choose antibiotics rather than other remedies like cough syrup.

I cannot afford to take time off, so I take them.

Alternatives are not really effective, antibiotics are stronger.

If it is really bad, I take it, but not otherwise.

Respondent stocks antibiotics at home for future use.

I do, but only if it is not expired.

Yes, because I know my symptoms.

Of course I share my medicine!

Medicine is expensive, of course I keep it!

Respondent does not consider the spread of drug resistance.

Why would it? It's not a disease!

Only if I breastfeed my child-the medicine might not work for the child anymore... (i.e. the chemicals from the medicine are passed on)

Note: Example responses in italics, based on prior qualitative research (Haenssgen et al., 2018a; Khine Zaw et al., 2018) and on cognitive interviews

Table 5 Sample characteristics of two rounds of census survey in three Thai villages

\begin{tabular}{|c|c|c|c|c|c|c|c|c|c|c|c|}
\hline \multirow[t]{2}{*}{ Variable } & & \multicolumn{5}{|c|}{ Survey Round I } & \multicolumn{5}{|c|}{ Survey Round II } \\
\hline & & Mean & Std. dev. & Min & Max & $n$ & Mean & Std. dev. & Min & Max & $n$ \\
\hline \multirow{4}{*}{ Activity } & $\%$ participated in educational activity: throughout & 0.00 & 0.00 & 0 & 0 & 626 & 0.13 & 0.33 & 0 & 1 & 640 \\
\hline & $\%$ participated in educational activity: partly & 0.00 & 0.00 & 0 & 0 & 626 & 0.02 & 0.12 & 0 & 1 & 640 \\
\hline & $\%$ heard about educational activity & 0.00 & 0.00 & 0 & 0 & 626 & 0.44 & 0.50 & 0 & 1 & 640 \\
\hline & $\%$ saw poster of educational activity & 0.00 & 0.00 & 0 & 0 & 626 & 0.41 & 0.49 & 0 & 1 & 640 \\
\hline \multirow[t]{11}{*}{ Demographic attributes } & Sex (\% female) & 0.54 & 0.50 & 0 & 1 & 626 & 0.54 & 0.50 & 0 & 1 & 640 \\
\hline & Age & 46.21 & 15.88 & 18 & 91 & 626 & 46.36 & 16.15 & 18 & 91 & 640 \\
\hline & Completed years of formal education & 4.46 & 4.88 & 0 & 18 & 626 & 4.43 & 4.87 & 0 & 19 & 640 \\
\hline & Wealth index (range: $0-1)^{a, b}$ & 0.56 & 0.12 & 0.17 & 0.89 & 291 & 0.55 & 0.12 & 0.17 & 0.89 & 304 \\
\hline & $\%$ speaking Thai & 0.84 & 0.37 & 0 & 1 & 626 & 0.83 & 0.37 & 0 & 1 & 640 \\
\hline & Ethnic group: Thai/Mueang & 0.34 & 0.47 & 0 & 1 & 626 & 0.35 & 0.48 & 0 & 1 & 640 \\
\hline & Ethnic group: Akha & 0.09 & 0.29 & 0 & 1 & 626 & 0.10 & 0.30 & 0 & 1 & 640 \\
\hline & Ethnic group: Lahu & 0.23 & 0.42 & 0 & 1 & 626 & 0.23 & 0.42 & 0 & 1 & 640 \\
\hline & Ethnic group: Mien & 0.27 & 0.45 & 0 & 1 & 626 & 0.26 & 0.44 & 0 & 1 & 640 \\
\hline & Ethnic group: Khamu & 0.07 & 0.25 & 0 & 1 & 626 & 0.06 & 0.24 & 0 & 1 & 640 \\
\hline & Ethnic group: Other & 0.01 & 0.08 & 0 & 1 & 626 & 0.01 & 0.08 & 0 & 1 & 640 \\
\hline \multirow[t]{7}{*}{ Antibiotic knowledge/attitudes } & $\%$ who have seen antibiotic capsules & 0.79 & 0.40 & 0 & 1 & 626 & 0.98 & 0.15 & 0 & 1 & 640 \\
\hline & $\%$ who have heard of drug resistance & 0.66 & 0.47 & 0 & 1 & 626 & 0.68 & 0.47 & 0 & 1 & 640 \\
\hline & $\%$ buy antibiotics over the counter (attitude) ${ }^{c}$ & 0.55 & 0.50 & 0 & 1 & 614 & 0.55 & 0.50 & 0 & 1 & 631 \\
\hline & $\%$ prefer antibiotics over alternatives (attitude) & 0.62 & 0.49 & 0 & 1 & 602 & 0.62 & 0.49 & 0 & 1 & 608 \\
\hline & $\%$ do not keep antibiotics for future use (knowledge) & 0.58 & 0.49 & 0 & 1 & 620 & 0.58 & 0.49 & 0 & 1 & 637 \\
\hline & $\%$ antibiotic resistance can spread (knowledge $)^{c}$ & 0.14 & 0.35 & 0 & 1 & 514 & 0.12 & 0.33 & 0 & 1 & 568 \\
\hline & No. of desirable knowledge/attitude answers (out of 4 ) & 1.84 & 1.04 & 0 & 4 & 626 & 1.81 & 1.07 & 0 & 4 & 640 \\
\hline \multirow[t]{9}{*}{ Treatment-seeking behaviourd,e } & Self-rated severity $(1=$ mild, $2=$ medium, $3=$ severe $)$ & 1.84 & 0.76 & 1 & 3 & 234 & 1.72 & 0.83 & 1 & 3 & 267 \\
\hline & Average duration of illness episode & 11.00 & 47.73 & 0 & 721 & 234 & 8.97 & 10.99 & 0 & 67 & 267 \\
\hline & Average no. of medicine courses received ${ }^{f}$ & 2.30 & 1.71 & 0 & 11 & 234 & 2.18 & 1.81 & 0 & 11 & 267 \\
\hline & Average no. of capsule/tablet-type medicine courses $g$ & 1.71 & 1.47 & 0 & 9 & 234 & 1.60 & 1.58 & 0 & 8 & 267 \\
\hline & $\%$ public providers (health centres, hospitals) & 0.38 & 0.49 & 0 & 1 & 234 & 0.31 & 0.46 & 0 & 1 & 267 \\
\hline & $\%$ private providers (clinics, hospitals, pharmacies) & 0.14 & 0.35 & 0 & 1 & 234 & 0.21 & 0.41 & 0 & 1 & 267 \\
\hline & $\%$ informal providers (grocery stores, healers) & 0.08 & 0.27 & 0 & 1 & 234 & 0.10 & 0.31 & 0 & 1 & 267 \\
\hline & $\%$ family and self-care & 0.90 & 0.30 & 0 & 1 & 234 & 0.93 & 0.26 & 0 & 1 & 267 \\
\hline & $\%$ others & 0.02 & 0.13 & 0 & 1 & 234 & 0.04 & 0.20 & 0 & 1 & 267 \\
\hline
\end{tabular}

a Average of 17 household assets and amenities on scale from 0 to 1

bHousehold level data

cSee Table 2 for associated knowledge/attitude questions

dillness-level data

eResolved acute illnesses experienced by respondent (excluding uncompleted episodes and illnesses/accidents of children under respondent's supervision)

"Number of courses" as in, "How many types of medicine did you receive during step x of your illness?" 
meaning that $87.5 \%$ (548) of the first-round respondents could be re-interviewed. We further collected 30 cognitive interviews within the larger study, 9 of which were collected in the three case study villages.

Analysis. We analysed the survey data across two survey rounds descriptively in a difference-in-difference framework to compare villagers who were and who were not exposed to the educational activity. ${ }^{12}$ We considered the outcome of the activity to be people's knowledge of and attitudes towards antibiotic use, and their treatment-seeking behaviour relating to healthcare utilisation and medicine use. We limited ourselves to general medicine access because earlier research had highlighted the generally high rates of medicine use in Thailand (WHO SEARO, 2016, p. 47) and in order to accommodate people's uncertainty when describing medicine that might have been an antibiotic (Tangcharoensathien et al., 2018). In addition to these overall outcomes for Research Question 1, the descriptive analysis also involved a specific analysis of contextual factors for Research Question 2:

1. interpretations of and exclusion from the activity by language ability;

2. the distribution of results across physical and health system landscapes (with a focus on public health campaigns and healthcare access), and

3. the relationship between the involvement of social contacts during people's illnesses and activity outcomes.

Aside from descriptive statistical analysis, we used geographical information from the survey to explore the distribution of outcomes through visual inspection of the geo-information coded with respondents' characteristics (antibiotic knowledge/attitudes, treatment choices, ethnic/linguistic background). Qualitative data complemented all parts of the quantitative data analysis through triangulation and contextualisation. We used holistic (rather than categorial) content analysis using field notes (educational activity observations and survey team reflections) and cognitive interview transcripts (Lieblich et al., 1998), which we screened and synthesised according to their relation to specific outcome variables and analysis topics.

The analysis of the quantitative and qualitative analysis proceeded independently, but the process of triangulating the quantitative findings using the qualitative material prompted further and more detailed quantitative analyses (e.g. into the sources of medicine access following reports of idiosyncratic medicine access patterns in one of the case study villages). The quantitative data was analysed by the project leader $(\mathrm{MJH})$ using Stata 13 (StataCorp, 2013); the qualitative data was analysed by the Thai leader of the current study (NC) using standard word processing software. The research team members involved in conceptualising the educational activity (NC, PW, TX, YKZ) discussed the qualitative and quantitative results and reflected on any disagreements arising between them.

\section{Results}

We will present the results according to the research questions. Section "Research question 1: overarching outcomes" will focus on the overarching direct and indirect outcomes of the educational activity in terms of health-related attitudes and behaviours, the section "Research question 2: contextual variation" will analyse the distribution of the outcomes with a specific focus on language barriers, on physical and health system landscapes, and on social networks.

Research question 1: overarching outcomes. Overall, the educational activity was associated with a change in villagers' antibiotic-related knowledge and attitudes, as well as treatmentseeking behaviour. Despite a mild direct alignment of attitudes and behaviours with the WHO messages, the association was highly heterogeneous, varying across villages as well as across channels of direct and indirect communication. Contextual factors, which we explore in the following section, help explain this surprising mixture of intended and unintended outcomes.

Figure 8 summarises the overall outcomes of the educational activity across the three villages, drawing on the matched panel data set and comparing the before-and-after situation (R.1, R.2) for people who were exposed directly (participation, solid green line) and indirectly (conversations, solid yellow line; posters, solid magenta line) and those who were not (i.e. non-participants or people who had not otherwise talked about the activity or seen the posters, depicted through dashed lines of the corresponding colours). The underlying difference-in-difference statistics are presented in Supplementary Tables S1, S2, and S3.

Panels a 1 and 22 of Fig. 8 present changes in antibiotic-related attitudes and awareness. Panel al compares the scores (0-4) of "desirable" answers to the four antibiotic questions in Table 4, section "Research design". In all three villages, the educational activity was consistently associated with more "desirable" responses compared to indirect communication and unexposed individuals (in the case of the Chiang Rai village, it counteracted otherwise mildly declining time trends). In contrast, exposure to indirect communication via conversations or the posters followed (or mildly accentuated) the general trend, which suggests that they were not related to attitudes and knowledge. The activity's outcomes on people's awareness of the term "drug resistance" (regardless of the interpretation of the term) are presented in Panel a2. Whereas participation in the activity was not linked to higher levels of awareness beyond the general trend in the Chiang Khong and Chiang Rai villages, we could observe a strong positive association in the Mae Fah Luang village. All three villages also demonstrated a positive association between poster exposure and people's response to the question whether they heard of drug resistance, while no such relationship emerged for people who conversed about the activity (note that non-Thai speakers were under-represented in poster exposure but less so in the conversations, see next section). These results thus far suggest that the educational activity was linked to medically more "desirable" antibiotic knowledge and attitudes, and poster exposure, too, exhibited a mildly positive link to nominal awareness of drug resistance (we discuss in the section "Discussion" to what extent this might have been the result of more pronounced "social desirability" biases).

In Panels b1 and b2 of Fig. 8, we consider the overall link between the educational activity and healthcare choices during acute illnesses or accidents. We summarised the treatment choices into formal treatment (public health centres and hospitals, private clinics and hospitals, pharmacies) and informal treatment (local stores and traditional healers). Participants of the activity were less likely to seek treatment from informal healthcare providers like shops and traditional healers in all three villages. Ironically, however, indirect forms of communication were linked in almost all cases to higher informal healthcare access, often exceeding the existing trend. The link between the activity and formal healthcare access was yet more mixed, as all direct and indirect exposure to the activity coincided with lower formal healthcare utilisation in Chiang Khong and higher utilisation in Mae Fah Luang. Formal healthcare utilisation in the Chiang Rai village was largely independent of the activity, except for the participants of the activity, who would exhibit comparatively lower formal healthcare access rates (contrary to the content of the activity, which suggested consultations with qualified and regulated medical practitioners). 

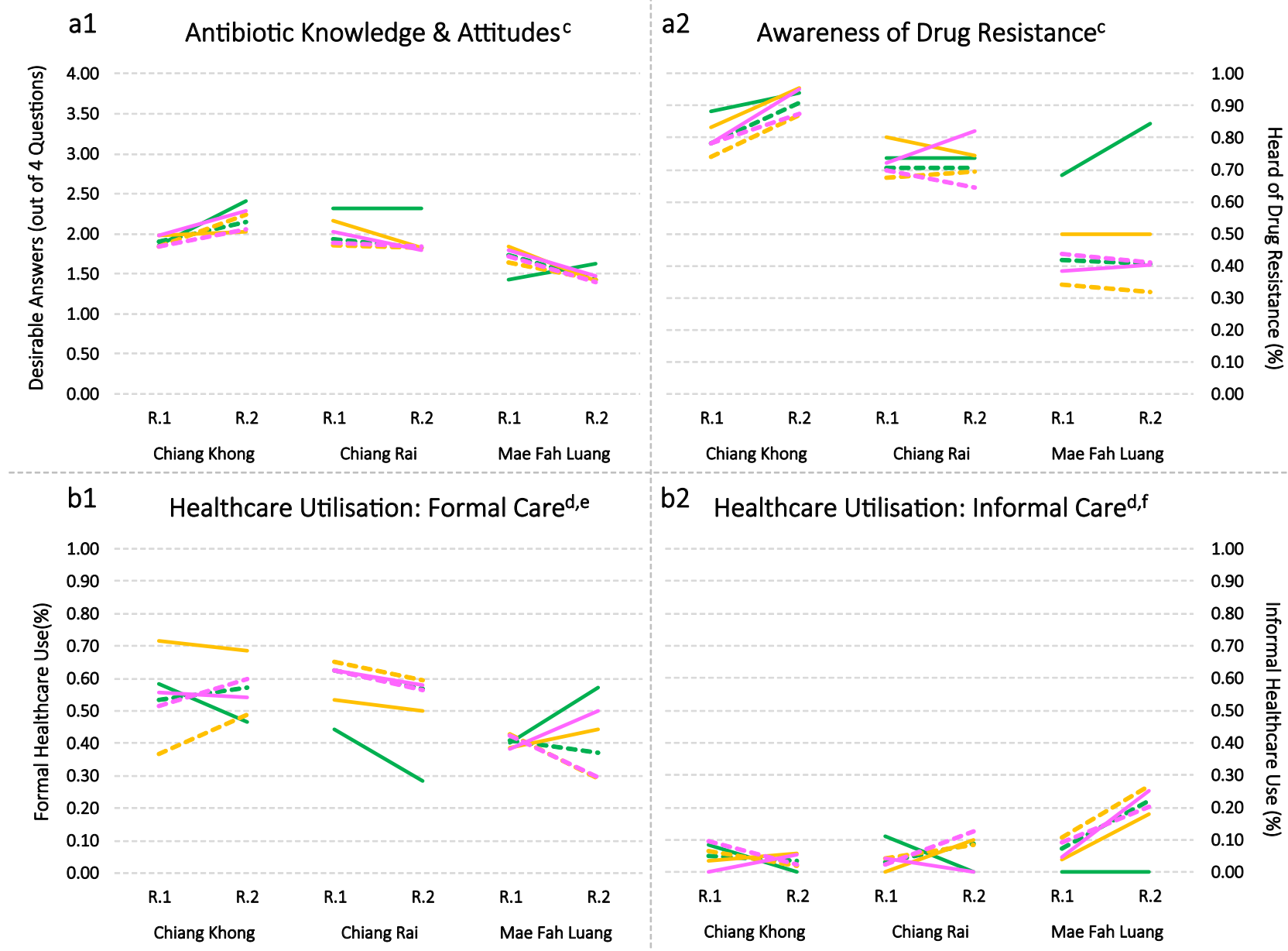

\section{b2 Healthcare Utilisation: Informal Care $\mathrm{d}^{\mathrm{f} f}$}
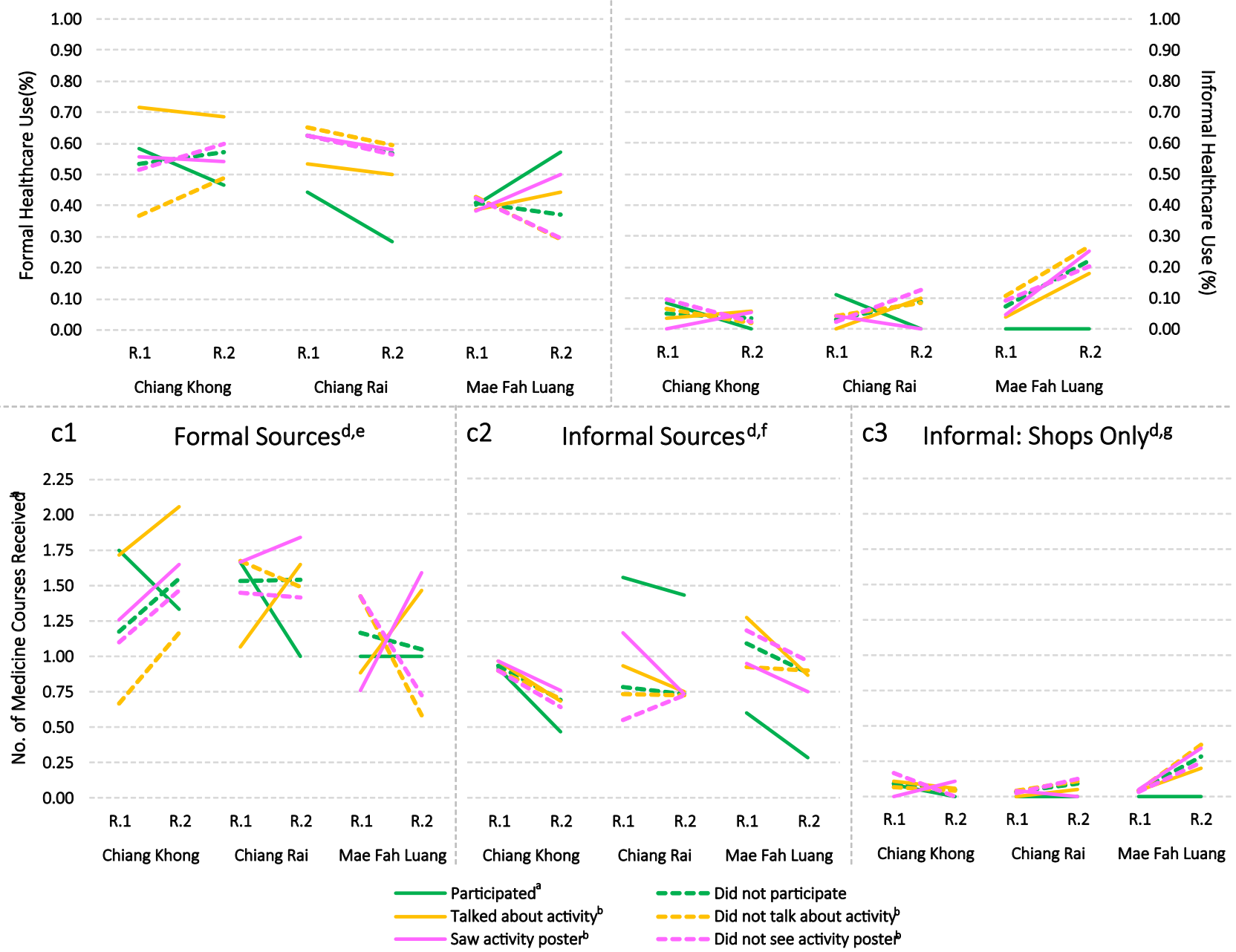

Fig. 8 Overall outcomes of educational activity: Participation (solid green lines) was associated with intended responses in almost all cases, whereas indirect exposure (solid yellow and magenta lines) showed mixed associations. a1 and a2 display changes in antibiotic-related knowledge, b1 and b2 show reported healthcare choices during past illnesses, and $\mathbf{c 1}, \mathbf{c} \mathbf{2}$ and $\mathbf{c} \mathbf{3}$ depict the sources of medicine during these illnesses. Notes: Among non-participants, $43 \%$ neither saw the poster nor talked about the activity, $21 \%$ saw the poster, $17 \%$ talked about the activity, and $19 \%$ both saw the poster and talked about the activity. ${ }^{a}$ Only participants who attended activity throughout (omitting 10 partial attendees). bSub-sample, including non-participants only. CIndividuallevel data of matched panel data set $(n=1096$, i.e. 548 observations per survey round). dIllness episode level $(n=474)$. Samples include only completed illnesses experienced by respondents themselves (omitting illness episodes of children in their household). ePublic health centres, public hospitals, private clinics, pharmacies, private hospitals. ' Local stores, traditional healers (for medicine use, also medicine stored at home or received from family/friends). gSubset of informal sources. "humber of courses" as in, "How many types of medicine did you receive during step x of your illness?" 


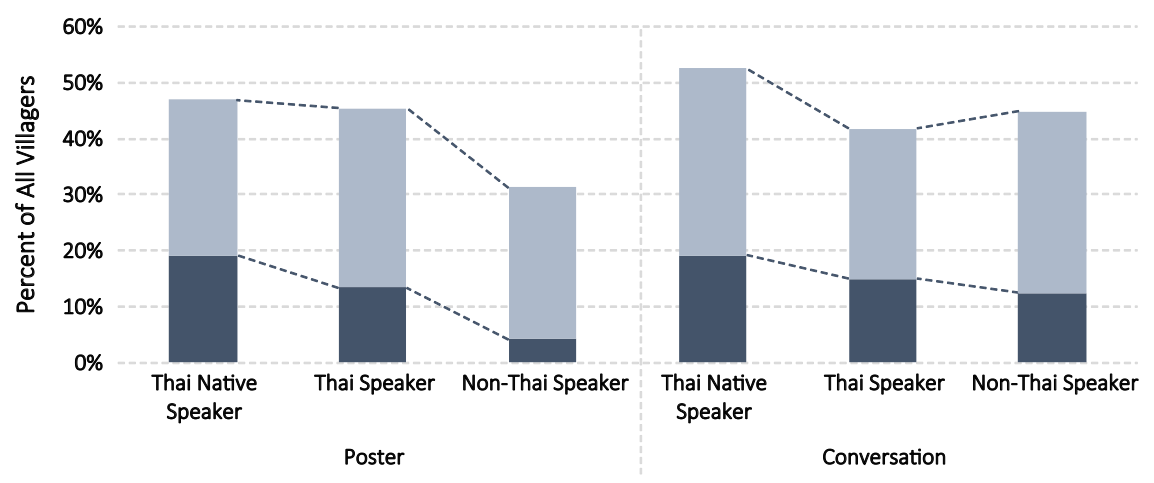

- Saw Poster / Talked About Activity

- Recalled Topics Related to Educational Activity Content

Fig. 9 Topics that people recalled from talking about the activity and seeing the posters, and the share of topics that related to the content of the educational activity: While the share of activity-related content of both poster impressions and conversations declined across non-native Thai speakers and non-Thai speakers, the decline was most pronounced for non-Thai speakers consulting the posters. Non-Thai speakers also appeared more likely to not have noticed the posters. Notes: "Endline" (R.2) of matched panel data set $(n=548)$. Sub-samples by language are $n=198$ (native Thai speakers), $n=254$ (Thai speakers), and $n=96$ (non-Thai speakers). Among all people who saw the posters, recall of activity topics was $41 \%$ (native Thai speakers), $29 \%$ (Thai speakers), and 13\% (non-Thai speakers); and activity-related topics were discussed by 37\% (native Thai speakers), 36\% (Thai speakers), and 28\% (non-Thai speakers) of the people who talked about the activity. Topics related to educational activity content include "using medicine correctly," "antibiotics/anti-inflammatory medicine," going to the doctor when sick," drug resistance" and "germs"

In Panels c1-c3, we explore the sources of medicine access during these illness episodes. All forms of direct and indirect exposure were linked to reduced medicine access from informal sources (Panel c2). The general declining trend thereby masked shifts in the internal composition of informal sources, whereby access to medicines from shops increased among people in the Chiang Rai and Mae Fah Luang villages who had not participated in the activity (Panel c3). Increases in medicine from formal healthcare providers (Panel $\mathrm{cl}$ )-which were especially pronounced among groups who were exposed indirectly to the activity-had in almost all cases private sources like pharmacies and private clinics. Therefore, and contrary to expectations, the educational activity was often linked indirectly and sometimes directly to higher access to medicines, especially from private sources. While this could have detrimental consequences of increasing out-of-pocket healthcare costs, the reported behaviour of participants was typically in line with the content of the educational activity: compared to unexposed groups, the activity participants reported unambiguously lower unsupervised use of medicine from informal sources.

In response to Research Question 1, the overarching outcomes of the educational activity were mixed. Direct exposure was linked to a mild alignment of attitudes and behaviours with WHO positions, but the consequences of indirect exposure were heterogeneous and potentially problematic. The varied and opposing trends suggest that contextual factors and interpretive processes interlaced the reception of, and action on, the messages within the educational activity-which we explore in the following section.

Research question 2: contextual variation. Adhering to the conceptual framework, we divide our examination of contextual factors into translational processes, the distribution of outcomes across the physical and health system landscape, and the possible pathway to impact via effects on social networks in the village. The short answer to Research Question 2 based on this analysis will be that especially the language and health system contexts of the activity shaped the distribution of its outcomes, but in unexpected ways beyond the control of the activity.

Translation, language barriers, and social exclusion. Based on what we learned from the poster-making session, the activity participants interpreted our messages in varied terms-including for instance accurate representations of drug resistance (in one instance even writing the English words "drug resistance"), applying messages for antibiotics to all types of medicine ("consult the doctor before you take any medicine"), or generic messages that were not actually part of the activity ("eat nutritious food"). This section explores how, although the team discussed the interpretations and edited the posters, information continued to be re-translated and re-interpreted during its diffusion within the villages. Thai language ability influenced this process. We will show that non-Thai speakers were more likely to remain unexposed and more likely to retain themes relating to the content of the activity, but also less likely than Thai speakers to articulate potentially adverse interpretations (e.g. medicine being "dangerous"). The next sub-section will further link the physical and health system context to the outcomes of the activity.

In Figs 9 and 10 (Supplementary Table S4), we summarise the relationship between language (Thai native speakers, people who speak Thai as a second language, non-Thai speakers) and the topics that people recalled from their conversations about the activity and the exposure to posters. Figure 9 considers the population share who were exposed to conversations and posters (irrespective of their attendance of the activity; total length of bars); the dark bars represent the fraction of the reported conversation/poster topics that related directly to the content of the educational activity. The left part of the figure indicates that non-Thai speakers reported up to 16-percentage-points lower exposure to the posters and were furthermore less likely to relate the poster to the messages of the activity.

For the groups who talked about the activity or saw the posters, Fig. 10 displays the topics that arose across the three language groups. Most poster and conversation topics related generally to the activity and entertainment (Topics 1a and 1b). Non-Thai speakers were under-represented or non-existent among the themes that related directly to the activity content $(2 a-2 e)$. For example, only $3 \%$ of the non-Thai speakers recalled from the posters the topics of "using medicine correctly" (2a) and "antiinflammatory medicine/antibiotics" (2b), compared to $35 \%$ and $19 \%$ of Thai native speakers. The only exception was the poster topic of "going to the doctor when sick," which non-Thai speakers recognised at a mildly higher rate (7\%) than Thai native speakers $(5 \%)$. In the conversations, non-Thai speakers were 


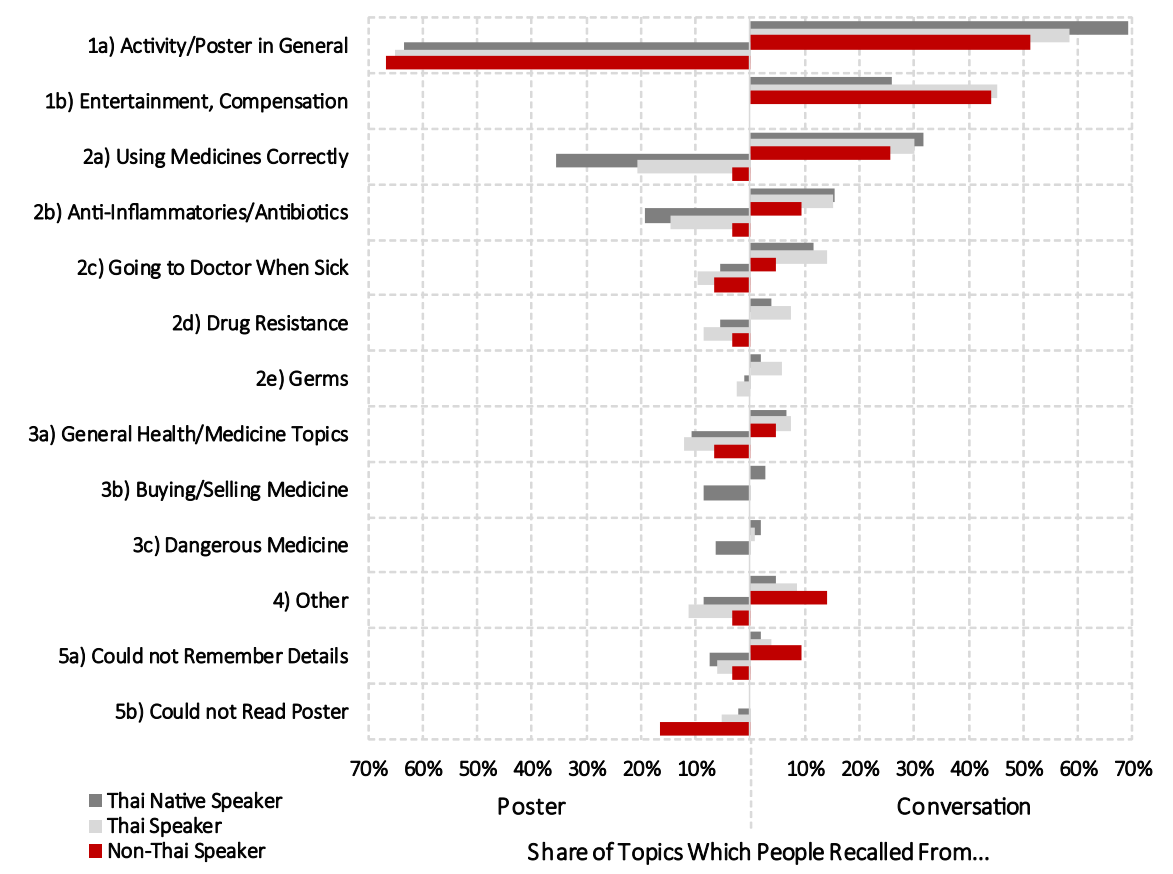

Fig. 10 Relationship between language and the topics that people recall from posters and conversations about the educational activity: Topics related to the activity in general (1a) and entertainment (1b) were by far most prevalent for posters and conversations, and similarly common for Thai speakers and nonThai speakers. Non-Thai speakers were otherwise under-represented or non-existent among activity-related topics (2a-2e), especially so for posters. Thai speakers were also more likely to consider general health and well-being (3a), as well as more problematic themes of "dangerous medicine" (3c). The theme "buying/selling medicine" (3b) arose in the Chiang Khong village, where posters were displayed at shops and rumoured to be part of public health campaigns to stop all informal medicine sales. Non-Thai speakers were on average older and more likely to not remember details of the conversations and posters (5a), but they also found it difficult to read the posters (5b), especially when nobody would assist them. "Other" poster topics (4) included, e.g. announcements of the activity; "other" conversation topics (4) included e.g. "drawing maps, poster-making" and exclusion from activity. Notes: Data only for groups who indicated exposure to conversations or posters. Poster sub-samples by language are $n=93$ (native Thai speakers), $n=115$ (Thai speakers), and $n=30$ (non-Thai speakers). Conversation sub-samples by language are $n=104$ (native Thai speakers), $n=106$ (Thai speakers), and $n=43$ (non-Thai speakers)

more likely to raise "other" topics, like the fact that there was a public announcement by the village head about the activity. Because non-Thai speakers also tended to be older, they appeared to have more difficulty recalling what the conversations were about. More evident, however, were their difficulties reading the posters, especially in situations when no other villager would assist them, making "Could not read the poster" (5b) with $17 \%$ the second-highest response after the general poster design (1a, $67 \%)$ and before health and medicine in general $(3 a, 7 \%)^{13}$ and "going to the doctor when sick" (2c, 7\%). The figures therefore demonstrate that non-Thai speakers had less opportunity to derive activity-related information from the conversations as well as from the posters, and the posters were indeed more likely to remain "invisible" for this group. At the same time, our respondents (e.g. shopkeepers who exhibited the posters) informed our survey team that other villagers occasionally helped overcome language barriers by explaining and discussing the posters with Thai-illiterate people, which is reminiscent of the argument that benefits of literacy can extend beyond the individual to others (Basu et al., 2001, p. 664). Yet, the ability to read Thai also entailed interpretations that contradicted the content of the activity, as $6 \%$ of the poster topics considered by Thai speakers alluded to "dangerous medicines" (3c).

The ambiguous role of language was visible in our qualitative material as well. We did hear complaints from villagers that they could not read the posters or that nobody helped them to understand their content. However, even Thai speakers struggled with the interpretation of our messages during the activity, and non-participating Thai speakers would often only give the poster a passing glance during which they might absorb only salient parts of the information (presumably focused on graphical elements emphasising medicine, capsules, and healthcare). For example, in the Chiang Rai village, people commonly reported to our survey team that they had seen but did not have time to read the poster. People who did read the poster and looked for further information tended to be those who had lived in major cities before. A further complication was that, even though the posters used the otherwise common and unambiguous Thai term "anti-inflammatories" as antibiotics, many people in the village rather considered antibiotics in terms of brand names like ทีซี-มั้ยซิน ${ }^{\circledR}(T C-M y c i n)$ or specific medicine names like "คลอแรม" ("chloram," short for chloramphenicol). Such language ambiguities surrounding antibiotics could have made it yet more difficult for people to relate the poster to their own health behaviour. ${ }^{14}$

Language barriers therefore rendered information inconceivable especially for non-Thai speakers, but language ability was no guarantee that the concepts of the educational activity resonated with people's notions of illness and medicine. Only a minority of Thai speakers referred directly to the content of the activity 3 months after the event, and Thai language ability was also linked to the emergence of problematic interpretations of "dangerous" medicines.

Influence of physical and health system landscapes. We will highlight in this sub-section that potentially problematic themes arose in interaction with people's physical and health system context. We will first consider interactions between the activity and parallel public health campaigns in the Chiang Khong village, 
then examine how healthcare access shaped people's responses, and lastly provide a broader overview of the geographic distribution of outcomes.

Parallel public health campaigns. The case of the Chiang Khong village illustrated how, even in the absence of language barriers, messages from the activity were re-interpreted in the context of parallel public health campaigns. The general decline of medicine from informal sources (see previous Fig. 8, Panel c2) resonated with the looming though misunderstood threat of penalties for restricted informal medicines sales. The shops' reactions to the public health intervention made it more difficult for villagers to access medicine that was previously available within the village. A troubled villager explained in a cognitive interview that,

"It's going to be hard for us. Say if I only have a headache, [I'd only need] Para[cetamol]. Say for stomach ache or irritation, a cold, or cough... Or Tiffy! [A combined drug with paracetamol and chlorpheniramine.] They don't allow those to be sold [in local shops] anymore. Doing that is pressing us indirectly. [...] It's $9-10 \mathrm{~km}$ to get to the hospital, do they expect them [other villagers] to walk there just to get a set of Para? [...] It's inconvenient. It's okay for those who have a car. But what about people who don't?" (Cognitive Interview)

The temporal co-incidence of the public health intervention with our activity meant that villagers associated us with the withdrawal of medicines from shops, which was not explained clearly to them by the shop owners, and which created mild antagonism among the village population toward the survey team.

When we presented three posters at the local shop that stopped selling medicine, we were later informed by the shop owner that people commonly conflated the poster with the complete cessation of medicine sales and reinterpreted the messages on the poster that say "you [patients] should not buy antiinflammatory medicine without prescription" as "shops must not sell medicine." Because this nuance did not appear to be meaningfully different in the local context, people might have linked the poster to the local health policy changes-which would explain why the theme of "buying and selling medicines" only arose in this village, and only among people who could read (see previous Fig. 10, Theme 3b). The antagonism resulting from this re-interpretation and local appropriation of the messages may have led to resisting the activity content for people who were exposed to the poster, which is confirmed in the observation that this group was the only one in the Chiang Khong village whose medicine consumption from shops increased after the educational activity (see previous Fig. 8, Panel c3).

Indirect information from the activity via the posters was therefore both conceivable and applicable for people in the Chiang Khong village, but it was reinterpreted in a process of growing resistance to parallel public health campaigns.

Healthcare access and road construction. The Mae Fah Luang village offered an example of how healthcare access shaped responses to the activity. In the previous case, information from the activity was reconfigured in light of a parallel public health campaign. In Mae Fah Luang, information from the activity was also conceivable and actionable, but it was repurposed to encourage informal antibiotic sales in the context of remaining gaps in healthcare access.

One of the participants in the educational activity was the owner of a local shop. Once the team arrived for the re-survey 3 months later, she thanked them for educating the village about medicines ("We know much more about ways to take medicines now," Cognitive Interview), as a result of which she deemed herself more knowledgeable and started selling medicine including antibiotics. By apparently filling a gap in the local healthcare landscape, informal healthcare utilisation and medicine access increased for all groups except the participants of the activity (who remained at the zero level; see previous Fig. 8, Panels b2 and c3), and people tended to mention her more frequently as a common source of medicine in the second survey round.

Yet, the healthcare landscape was not static. The new road connection, opened shortly after the educational activity, also facilitated access to healthcare facilities in the nearby district headquarters. Prior to the road construction, a male villager explained,

"You wouldn't be able to go [out of the village] if it [the road] was like the past, too much dust. There'd be this much dust in the dry season [gestured hands, laughed], and this much mud during the rainy season. We wouldn't be able to drive a motorcycle [on this road], it's like that" (Cognitive Interview).

He went on to explain that, "Now the roads are good, so [old people or those without a motorcycle] would go to the doctor right away even for a minor illness" (Cognitive Interview). This suggests that the supply of both formal and informal healthcare increased during the study period, whereby activity participants' uptake of the increased supply was inclined towards formal sources (see Panels b1 and b2 in Fig. 8). The case of the Mae Fah Luang village thereby illustrated how healthcare supply conditions geared treatmentseeking behaviour towards formal sources for activity participants, and towards informal sources for non-participants.

Geographic distribution of outcomes. As a last step in the analysis of the physical and health system context, we summarise the outcomes of the educational activity geographically in Fig. 11. Row 1 illustrates changes in antibiotic-related knowledge and attitudes. In the peri-urban setting of Chiang Khong, $44 \%$ of the respondents had a higher and $28 \%$ had a lower score in the second survey round. In Chiang Rai, we observed increased scores among $31 \%$ of the respondents and lower scores among $36 \%$; and in Mae Fah Luang 28 and 46\%, respectively. Rows 2 and 3 display changes healthcare choices (formal healthcare access) and medicine sources (informal sources) during illnesses (using a subsample of individuals with illnesses in both survey rounds). Overall, the changes were distributed evenly within the villages and we only observed geographical heterogeneity in the Mae Fah Luang village, where almost all increases in formal healthcare utilisation and decreases in informal medicine access were concentrated geographically in the Lahu village segment (who also represented the majority of activity participants). Across the three villages, the relative increase in formal healthcare utilisation was least pronounced in the remote Chiang Rai village (14\% reported increased utilisation of formal healthcare) which represented the most difficult healthcare access conditions, followed by the periurban Chiang Khong village (24\%) where healthcare access was comparatively easy, and topped by the Mae Fah Luang mountain village (32\%) where the newly constructed road plausibly shifted treatment-seeking patterns.

In summary, we could observe variations of attitude and behaviour change across the different physical and health system contexts of the three villages. Unintended interpretations of parallel health policies interacted with and created resistance to the activity in Chiang Khong (via indirect channels of exposure); new road construction in the Mae Fah Luang village enabled participants to act on the information they received, while 


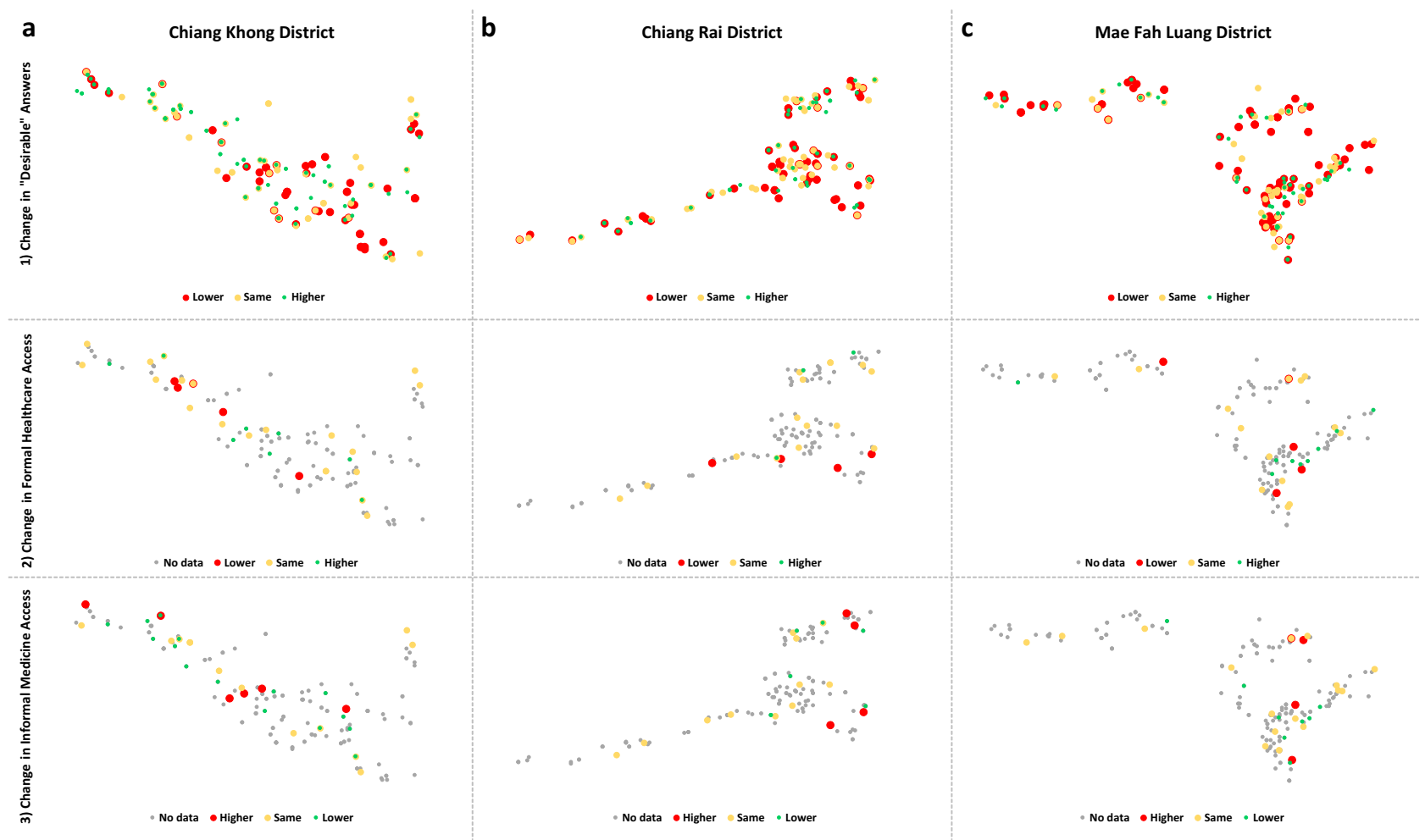

Fig. 11 Geographical overview of educational activity outcomes in case study villages: Changes in antibiotic-related attitudes (1) were distributed evenly across the villages, while increases in formal healthcare access (2) and reductions in informal medicine access (3) were concentrated among the Lahu segment in the Mae Fah Luang village c. Notes: "Endline" (R.2) data, matched panel data. $n=185 \mathbf{a}, n=167 \mathbf{b}, n=196 \mathbf{c}$. Marker size adjusted to distinguish overlapping responses. Rows $\mathbf{2}$ and $\mathbf{3}$ contain individual-level data from matched illness episodes in both survey rounds; $n=34 \mathbf{a}, n=22 \mathbf{b}, n=28 \mathbf{c}$

persistent healthcare access challenges also provided a market opportunity for informal antibiotic sales; and the isolation of the Chiang Rai village left behaviours mostly unaltered. As far as the distribution of ethnic and linguistic groups within the villages was concerned, we observed some degree of outcome concentration among the Lahu segment of the Mae Fah Luang village, but within-village variation more generally tended to not follow the geographical pattern of these groups. ${ }^{15}$ This suggests that, while social gradients evidently existed and mattered for the flow of information within the community, they could be bridged to some extent through an inclusive selection of individuals.

Influence on social networks. We now explore whether the educational activity was linked indirectly to health behaviours through a social network pathway. Although the educational activity did not explicitly recommend that people should seek treatment with the help of others, we assumed that the participation in the activity could create a new social support network among the participants, and that the participation could make participants more knowledgeable and thus more demanded resource persons for other villagers' illnesses.

When our team revisited the survey villages, their conversations with the villagers across all three sites consistently corroborated that the activity itself did not create a new social network. Similar to the implementation dynamics outlined in the section "Implementation process", the team learned that the activity was a general conversation item among people who knew each other already, thereby reproducing rather than reconfiguring the existing social networks. Such a reproduction of the village social network was evident for instance in the case of a shopkeeper in Chiang Khong, whose nodal social network position led her situation to become the common object of conversations within the village network. The social network was thereby not only a medium for activity-related content but also for rumours and new information that could work to its disadvantage. One exception to the reproduction of the social network, however, was the local shop owner in the Mae Fah Luang village, who signalled knowledge of pharmaceuticals and raised the informal supply thereof following the activity. These changing characteristics of the individual and thus the therapeutic landscape in the village led her to become a more central figure for people's illnesses.

Alas, less than five percent of all illness episodes across the three villages involved another villager who was not a family member, irrespective of the survey round or participation in the activity. This indicates that the activity did not contribute to creating new help networks. ${ }^{16}$ However, as we have shown in Fig. 12, our survey data indicated a noticeable general increase across the survey rounds in the number of illnesses that involved another person (i.e. a family member). Participation in the educational activity was unlikely to be the cause of these trends, which may rather stem from the week-long presence of the survey team in the village-questions about health and reflections on the involvement of others during one's illness may have provoked different behaviours. Other explanations might be that people were less likely to activate social support networks during the busy harvest period (i.e. the recall period during R.1), while the constraints relaxed during the dry season (R.2); or that seasonal variation in the epidemiological context influenced treatmentseeking patterns and social network activation. ${ }^{17}$ The survey team might have also received more trusting responses in the second survey round, but we observed a similarly positive trend in all 
three villages despite their different economic structures and the comparatively antagonistic environment in Chiang Khong.

Although possible, it remains debatable whether the longerterm presence of the survey team contributed indeed indirectly to increased social network activation in the three villages. Yet, if it did, then the question is whether such an involvement would be advantageous. We analyse this point in Table 6 , in which we compare medicine use and healthcare choices depending on social network activation and illness severity. We separated the analysis by self-described severity because of potential reverse causality, whereby more severe illnesses may be likely to prompt the involvement of other people and also involve different forms of behaviour. The comparison demonstrates that, across all three

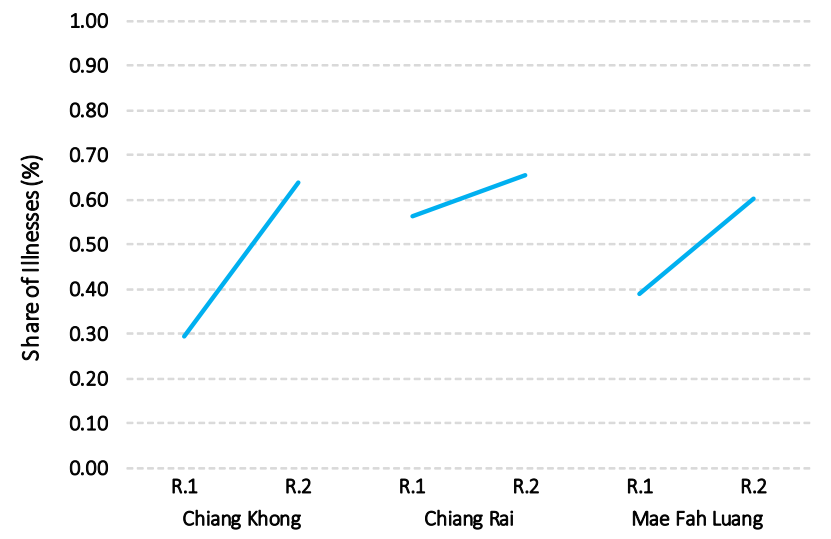

Fig. 12 Overall changes of illnesses involving at least one other person across survey rounds, irrespective of activity participation: While the share of illnesses involving other people increased consistently across both survey rounds, almost none $(<5 \%)$ of the illness episodes involved other villagers outside of the respondent's family. Owing to near-zero activation of village contacts during illnesses, it is unlikely that the activity contributed to the trend; broadly positive trend may have instead resulted from the week-long presence of the survey team in the village. Notes: Unmatched data, illness episode level $(n=474)$. Samples include only completed illnesses experienced by respondents themselves severity categories, the involvement of others was linked to increased medicine use. At the same time, illness episodes involving other people were also considerably more likely to involve formal healthcare providers, especially public health centres and hospitals. Although informal treatment also increased in the presence of other people in the case of self-described "mild" and "severe" conditions, formal healthcare utilisation was disproportionately higher. For example, for mild illnesses, the involvement of others was linked to 2 percentage-point higher informal healthcare access, 8 percentage-point higher private healthcare access, and 14 percentage-point higher public healthcare access. This pattern was also evident in the sources of medicine, which showed an unambiguous concentration among formal sources if at least one other person was involved during the illness. This suggests that social network activation was more likely to entail medicine prescription by trained healthcare staff, which is in line with the messages embedded in the educational activity.

In short, the educational activity did not create a new social network among or involving the participants. External factors rather contributed to increased activation of social support networks, in which case villagers' behaviour was more likely to align with WHO positions.

\section{Discussion}

Drawing on our analytical framework, the results demonstrate that the educational activity had a mixed relationship with people's attitudes and behaviours, which we hypothesised to operate through two pathways, mediated by the idiosyncratic context of each village. The findings are summarised in Fig. 13: In the content pathway, language barriers meant that information from the activity remained far-fetched, potentially excluding already disadvantaged groups (consider e.g. the concentration of favourable outcomes among activity participants in the Mae Fah Luang village, who were more likely to be Thai speakers). In contrast, inclusivity during the recruitment for the activity and the widespread indirect exposure suggested that ethnicity was not a factor contributing to social exclusion. Where translation was successful thus, it could align antibiotic-related attitudes with positions in WHO awarenessraising messages, but interactions with confounding public health

Table 6 Overall relationship between treatment-seeking behaviour and help networks, by self-perceived severity of illness

\begin{tabular}{|c|c|c|c|c|c|c|c|}
\hline & \multirow{2}{*}{$\begin{array}{l}\text { Illness severity } \\
\text { Illness involving } \\
\text { other people }\end{array}$} & \multicolumn{2}{|l|}{ Mild } & \multicolumn{2}{|l|}{ Moderate } & \multicolumn{2}{|l|}{ Severe } \\
\hline & & $\begin{array}{l}\text { Nobody } \\
\text { involved }\end{array}$ & $\begin{array}{l}\text { Others } \\
\text { involved }\end{array}$ & $\begin{array}{l}\text { Nobody } \\
\text { involved }\end{array}$ & $\begin{array}{l}\text { Others } \\
\text { involved }\end{array}$ & $\begin{array}{l}\text { Nobody } \\
\text { involved }\end{array}$ & $\begin{array}{l}\text { Others } \\
\text { involved }\end{array}$ \\
\hline \multicolumn{2}{|c|}{ Medicine courses received } & 1.41 & 1.65 & 2.28 & 2.70 & 2.83 & 3.47 \\
\hline \multirow[t]{5}{*}{ Healthcare choices } & Public treatment ${ }^{a}$ & 0.11 & 0.25 & 0.39 & 0.44 & 0.47 & 0.61 \\
\hline & Private treatment ${ }^{b}$ & 0.08 & 0.16 & 0.14 & 0.27 & 0.20 & 0.27 \\
\hline & Informal treatmentc & 0.09 & 0.11 & 0.10 & 0.06 & 0.07 & 0.12 \\
\hline & Self-care & 0.88 & 0.89 & 0.93 & 0.98 & 0.90 & 0.94 \\
\hline & Other & 0.00 & 0.04 & 0.07 & 0.02 & 0.07 & 0.02 \\
\hline \multirow[t]{3}{*}{ Medicine sources $^{d}$} & $\begin{array}{l}\text { Formal medicine } \\
\text { sources }^{\mathrm{e}}\end{array}$ & 0.45 & 0.82 & 1.31 & 1.79 & 1.83 & 2.68 \\
\hline & $\begin{array}{l}\text { Informal medicine } \\
\text { sources }^{f}\end{array}$ & 0.96 & 0.74 & 0.85 & 0.86 & 0.87 & 0.76 \\
\hline & Informal: Shops onlyg & 0.14 & 0.13 & 0.13 & 0.08 & 0.03 & 0.08 \\
\hline \multicolumn{2}{|l|}{$\begin{array}{l}\text { Number of } \\
\text { respondents }\end{array}$} & 132 & 96 & 72 & 86 & 30 & 85 \\
\hline \multicolumn{8}{|c|}{$\begin{array}{l}\text { Notes: Illness episode level. Samples include only completed illnesses experienced by the respondents then } \\
\text { apublic health centres, public hospitals } \\
\text { bPharmacies, private clinics, private hospitals } \\
\text { "Local stores, traditional healers } \\
\text { d"Number of courses" as in, "How many types of medicine did you receive during step x of your illness?" } \\
\text { epublic health centres, public hospitals, pharmacies, private clinics, private hospitals } \\
\text { fLocal stores, traditional healers, medicine stored at home or received from family/friends } \\
\text { gSubset of informal sources }\end{array}$} \\
\hline
\end{tabular}




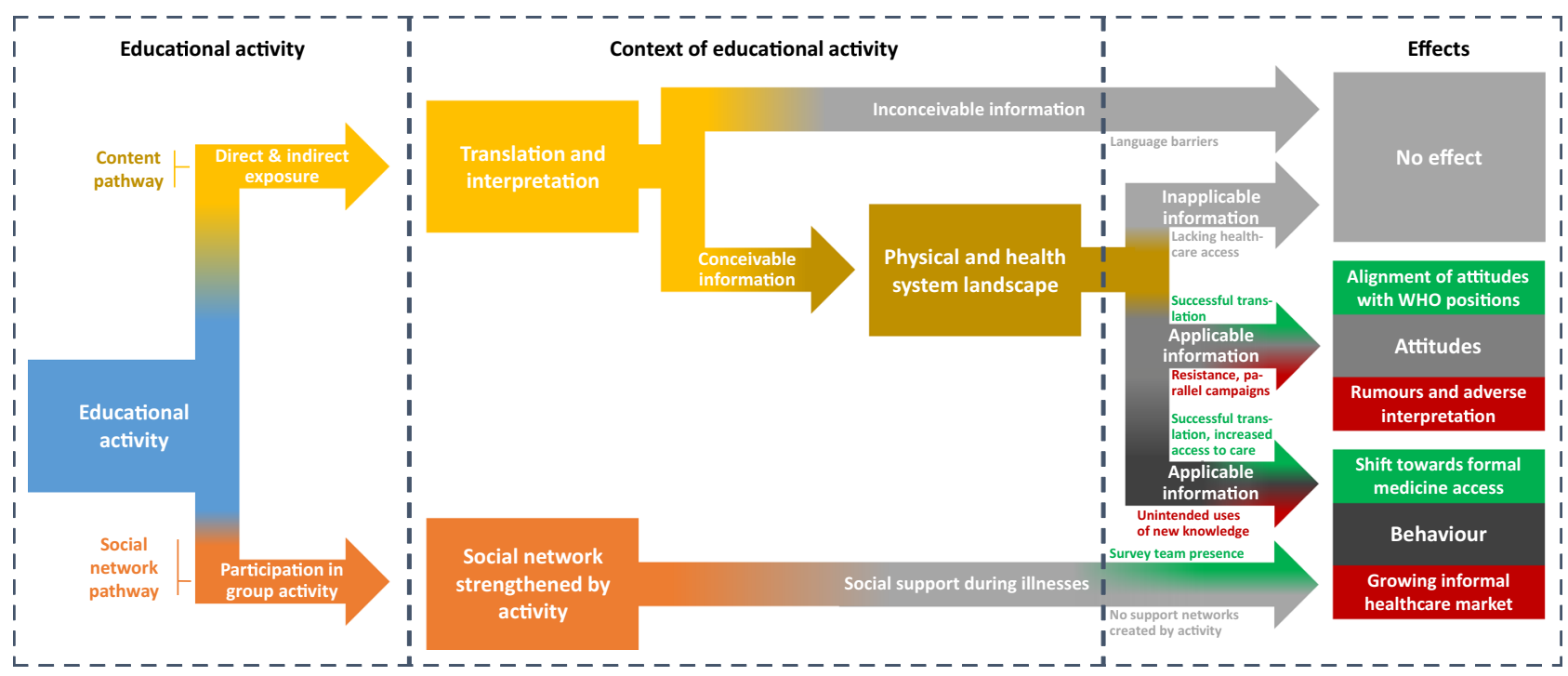

Fig. 13 Augmented conceptual framework, including the findings from the mixed-method analysis. In the content pathway, language barriers left information inconceivable, and conceivable information might not be acted upon if healthcare access barriers prevented it. Successful translation could align antibiotic-related attitudes with positions in WHO awareness-raising messages, but interactions with confounding public health campaigns entailed rumours and problematic interpretations. Health behaviour aligned with WHO messages especially where healthcare access was easy or improved through confounding road constructions, but residual healthcare challenges also legitimated informal sales of antibiotics. The social network pathway did not suggest an effect of the activity on social networks, but more general trends indicated that the extended survey team presence might instead have encouraged social support that shifted treatment seeking from informal to formal channels

messages also entailed the emergence of rumours and problematic interpretations of, for example, "dangerous medicine." Health behaviour also appeared to align with WHO messages where participants experienced relatively easy or improved access to healthcare facilities, especially in the case of confounding road constructions in the Chiang Rai village. Yet, residual difficulties in access to healthcare also meant that the content of the activity legitimated increased sales of antibiotics through informal channels, if the information had any actionable implications at all. The social network pathway did not suggest an association between the activity and social support networks; alternative explanations for the observed patterns might instead be that the extended survey team presence and/or seasonal change altered social support structures and thereby shifted treatment seeking from informal to formal channels and therefore aligned behaviours with WHO positions irrespective of the activity.

Our analysis therefore documents unforeseen and contextspecific interpretations and consequences that can result from educational messages relating to medicine and healing. Although the quantitative data suggested that participation in the activity yielded outcomes that were in line with the activity content, the overall link was small and possibly outweighed by unintended side-effects and externally driven changes in people's help networks. Even the re-interpretation of the educational activity content among participants coincided with a systemic change in the local healthcare landscape, boosting a merchant's confidence in their pharmaceutical knowledge and thus the informal supply of medicine including antibiotics. In other cases, the activity was re-defined as a public health intervention and blamed for reduced access to medicine from informal sources. Overall, the educational activity therefore was associated with changes in attitudes/ knowledge, treatment choices, and medicine use that were compatible with its themes, but the idiosyncratic responses across the three villages suggested that contextual factors like literacy, parallel health system developments, and social structures shaped the heterogeneous distribution of outcomes and the usefulness of the activity. The coincidental interaction with existing public health campaigns also provides evidence how one misunderstood message can encourage the misunderstanding of another.

Our study exhibited a number of limitations that qualify these interpretations. Firstly, we should entertain the possibility that part of the reported changes among participants may stem from more pronounced social desirability biases (i.e. activity participants being more conscious of what we would like to hear), whereas non-participants might have gradually become more trusting and "honest" about their answers. We saw direct evidence of social desirability in the field sites, with for instance the Mae Fah Luang shop owner preparing herself for her (cognitive) interview by watching YouTube videos about antibiotics, while other villagers perceived us as public health staff and indicated accordingly that they would not seek healthcare at local shops. This suggests that the survey responses after the educational activity were partly influenced by expectations of desirable answers rather than an actual change in attitudes and behaviours, and this would be consistent with the absence of a discernible relationship between indirect communication and the "desirability" questions. However, whether social desirability was systematically biased towards the activity and therefore skewed the results is questionable. For instance, people in Chiang Khong responded in many ways similarly to the other two villages even though the rumours about our activity could possibly have rendered them indifferent towards impressing our team; we received reports of villagers in Chiang Rai asking for further information about "drug resistance" at local health centres following our activity; and the range of topics that people retained from poster and conversation exposure was not evidently biased in favour of our activity and also included potentially problematic themes of "dangerous medicines." In addition, if the educational activity made it indeed clear what a "socially desirable" response would look like, then this might weaken the behavioural conclusions of the analysis, but it would not render communication altogether ineffective. 
Aside from response biases, we should also consider limitations associated with the study design. The educational activity did not take place in isolation but following a trust-building week-long survey period in which almost every adult in each village participated. This might have entailed systemic effects on the village level plus a stronger influence of the activity than otherwise. The activity itself, however, was not carried out by medical personnel, which could raise doubts about the legitimacy of our messages. Lastly, as a one-off activity in three case study villages, our research cannot aspire to make generalisable statements for Thailand or integrated AMR communication programmes as a whole. As far as lessons from this study are concerned, the focus should therefore be on "process" and "methods" rather than on the "product." In other words, the distinctive element of the educational activity was the harmonisation of the content following extensive social sciences work on local conceptions of illness and medicine, which we detailed in the section "Development and design". Yet, even if we agreed that the ensuing activity was successful in inspiring responses that were consistent with WHO messages, its local embeddedness makes it implausible to simply transplant it to another setting. Applying our lessons in other settings would instead require a long-term process involving (a) extensive qualitative research to understand the relationship between biomedical and local knowledge, (b) development of bespoke non-technical content like narratives and games with the help of local social scientists, (c) building trust with and understanding of the target groups, (d) feedback mechanisms like poster-making to understand the interpretation and continued translation of the content, and (e) a comprehensive assessment of its consequences. However, when considering the transferability of our findings to other settings, it would be insensible to ignore the ungovernable implications of indirect exposure to the activity. Rather than providing content, it might in fact be more important (and successful) to strengthen social support structures in rural societies and to enable an environment where recommended healthcare choices are feasible.

Our methodological approach offers a toolkit for understanding the direct, indirect, positive, and negative consequences of AMR communication, which can inform the evaluation of public engagement activities (be they isolated or programmatic; Thomson et al., 2013). We recommend that future public engagement and AMR communication projects explore and articulate the mechanisms leading to the expected outcomes, recognise potentially detrimental outcomes (e.g. taking our findings as a starting point), and choose evaluation methods that are suitable to detect them. Ambiguous and unintended interpretations thereby do not necessarily mean that a project is unsuccessful, and a recent workshop by the Wellcome Trust argued that "funders should be sufficiently flexible and understand the unpredictable nature of [public engagement projects using creative means of expression] to allow them to flourish" (Austen, 2016, p. 44). However, good intentions, open-endedness, and unpredictability do not relieve public engagement activities like ours of the need to be relevant, effective, efficient, and sustainable (OECD Development Assistance Committee, 1991, 2010).

\section{Conclusion}

This study aimed to contribute to the understanding of the consequences (and their contextual influences) when sharing antibiotic-related information in a rural middle-income setting. Our research questions focused on the overall consequences of an antibiotic-themed educational activity in three northern Thai villages, and whether contextual factors would influence the distribution of these consequences. The conceptual framework that guided the enquiry hypothesised two pathways through which effects of the activity might materialise, namely by the provision of content and through effects on the village social network. We used a mixed-method triangulation design involving two rounds of complete censuses together with supplementary qualitative information from activity observations and cognitive interviews.

Our answer to Research Question 1 was that the educational activity was primarily linked to a mild alignment of people's health-related attitudes and behaviours with WHO recommendations. The broader consequences were mixed and potentially problematic, however. Among the indirect consequences were for instance rumours and resistance to the activity, as well as increased informal healthcare utilisation. The answer to Research Question 2 was that language barriers limited people's response to the activity, and variations in the healthcare landscape were linked to increased antibiotic sales, rumours, and public resistance. In addition, social network changes did not appear emanate from the activity itself, but may have rather been a result of survey team presence and/or seasonal variation of social support structures, aligning behaviours irrespective of the activity.

Our findings lead us to hypothesise that such mixed and potentially problematic consequences may also result from other AMR-related communication campaigns and deserve urgent scrutiny given the scale of global awareness campaigns. To this end, we recommend further mixed-method assessments with a special focus on the indirect effects of AMR communication campaigns and other public engagement activities in order to build a knowledge base of cost-effective, target group specific, and locally appropriate activities. Mandatory two-directional knowledge exchange components could further help understand mismatches between the provided information and the local context and concepts underlying AMR.

Although this recommendation may imply that there ought to be better evaluation of more engagement and communication activities, we also invite fundamental reflection on the discourse and the approach to the social dimensions of AMR. High-level AMR debates and policy documents are emphasising the importance of education and awareness-raising to alleviate "problematic" antibiotic use in the general population. The medical discourse goes as far as assigning blame to the public for not recognising the importance and their own responsibility for limiting AMR (Hawkings et al., 2007, p. 1159). Our experiences and mixed findings suggest that it may indeed be the case that individuals in precarious circumstances have more pressing priorities and are therefore unlikely to change their behaviour once they have been "educated." Popular overuse of antibiotics may only be the symptom of a larger problem of precarious living conditions and lacking social support, which could not be rectified with health policy interventions alone.

Received: 18 May 2018 Accepted: 10 January 2019 Published online: 26 February 2019

\section{Notes}

1 We do not attempt here to define public or community engagement but rather speak to the broad area of activities that involve interactions with non-academic audiences in health research and practice. In the context of the present study, this means that we considered the interactions with villagers during our educational activity as "public engagement" (i.e. the information we shared, and the views we received), but not our surveys and cognitive interviews (as they represent standard social research methodology). For a discussion of definitions of community engagement in health, see Tindana et al. (2007). 
2 The messages included, "only use antibiotics when prescribed by a certified health professional," "never demand antibiotics if your health worker says you don't need them," "always follow your health worker's advice when using antibiotics," and "never share or use leftover antibiotics" (see e.g. WHO, 2016).

3 A related point is that mass media communication is also prone to over-simplifying AMR communication as a human health behaviour problem, thereby diminishing structural determinants of behaviour and what is in academia often referred to as a "one health" problem involving animal and environmental health alongside human health.

4 We do not rule out here that new or stronger social networks and the involvement of other people can also have detrimental consequences, see e.g. Villalonga-Olives and Kawachi (2017).

5 As opposed to the northern Thai dialect, owing to language ability of the team of volunteers.

6 ฮานี้บ่าเฮ้ย or $\mathrm{Ha}$ Nee $\mathrm{Ba}$ Hoey-a traditional song about a romantic relationship between two northern Thai villagers.

7 Please note that, here and in the remainder of this manuscript, we refer to the notion of "dangerous drugs" (ยาอันตราย) as a colloquial term rather than to the legal category defined in the Thai Drug Act, B.E. 2510 (1967) and its most recent amendment (Government of Thailand, 2018, 1967).

8 Education and wealth information based on our survey data.

9 Our respondents could typically speak both northern and central Thai dialects.

10 A practical consequence of this contextualisation was for instance more effective coding of open responses to the survey questions "What do you call this medicine?" (following the presentation of common antibiotics in capsule form) and "What symptoms or illnesses would you use [antibiotics] for?" Note, however, that the survey instrument itself was static and did not change in response to the educational activity.

11 For example, insights from the cognitive interviews led us to add more specific questions on social networks after we learned that health-related interactions were prompted by asking respondents first on a range of different healthcare providers available to them.

12 Note that statistical hypothesis testing is not needed where complete census data is available. Considering that the village census responses are neither independent of each other nor a random sample of the Chiang Rai rural population, inferential statistics are not applicable to this data set.

13 Topic 3a can also be interpreted as an easy "default" answer category for respondents who were unsure what to say, considering that the mentioned topics in this category like "nutritious food" or "exercising" are heavily emphasised in school curricula and the media, even if their meaning remains elusive. Incidentally, "using medicines correctly" can be understood as one of these default categories as well.

14 As part of the broader research project, we will explore in future publications how people's conceptions of medicine shape their treatment-seeking behaviour and their response to the educational activity. For illustration, consider that prior to the educational activity, $23 \%$ of the villagers in Chiang Khong, $27 \%$ in Chiang Rai, and $43 \%$ in Mae Fah Luang did not recognise images of common antibiotics. The most common description of the medicine was "anti-inflammatory medicine" by $58 \%$ of all respondents in the first survey round, followed by "germ killer" with $3 \%$ and "chloram" with 2\%-aside from a wide-ranging category of other antibiotic and nonantibiotic names that comprised $21 \%$ of all responses. These fractions shifted substantially in the second survey round (to $87 \%, 21 \%, 13 \%$, and $35 \%$, respectively) in line with a lower share of people not recognising the shown medicine (3\% in Chiang Khong, 5\% in Chiang Rai, and $11 \%$ in Mae Fah Luang), which was partly a result of the survey instrument itself.

15 The changes of antibiotic knowledge and attitude pointed in similar directions for all ethnic groups (except Thai in the Chiang Rai village) irrespective of their exposure/ non-exposure to the educational activity.

16 In the way the survey questions were constructed, shop owners would not be considered part of the help network but rather a "healthcare provider" who was accessed during an illness.

17 Greer et al. (2018, p. 6) demonstrated for instance that patients on the primary care level in Chiang Rai district were more likely to be prescribed with an antibiotic during the rainy season. In the present study, however, we are not able to ascertain the extent to which the epidemiological context was responsible for the activation of help networks.

\section{References}

Allison PD, Higginson P, Martin S (2017) Antibiotic resistance awareness: a public engagement approach for all pharmacists. Int J Pharm Pract 25(1):93-96

Arnold JS, Fernandez-Gimenez M (2007) Building social capital through participatory research: an analysis of collaboration on Tohono O'odham Tribal Rangelands in Arizona. Soc Nat Resour 20(6):481-495

Austen K (2016) The art of health: exploring creative engagement with research [workshop report]. Wellcome Trust, Mumbai

Basu K, Narayan A, Ravallion M (2001) Is literacy shared within households? Theory and evidence for Bangladesh. Labour Econ 8(6):649-665
Batura N, Cuevas C, Khan M, Wiseman V (2018) How effective and cost-effective are behaviour change interventions in improving the prescription and use of antibiotics in low-income and middle-income countries? A protocol for a systematic review. BMJ Open 8(5):e021517

Bull R, Petts J, Evans J (2008) Social learning from public engagement: dreaming the impossible? J Environ Plan Manag 51(5):701-716

Bull R, Petts J, Evans J (2010) The importance of context for effective public engagement: learning from the governance of waste. J Environ Plan Manag 53(8):991-1009

Carrion ML (2018) "You need to do your research": vaccines, contestable science, and maternal epistemology. Public Underst Sci 27(3):310-324

Chereau F, Opatowski L, Tourdjman M, Vong S (2017) Risk assessment for antibiotic resistance in South East Asia. BMJ, 358(Suppl. 1):e021517

Cho H, Salmon CT (2007) Unintended effects of health communication campaigns. J Commun 57(2):293-317

Chuengsatiansup K, Sringernyuang L, Paonil W (2000) Community drug use in Thailand: a situational review. Task Force on Situation Review of Community Drug Use in Thailand, Bangkok

Cohen ER, Masum H, Berndtson K, Saunders V, Hadfield T, Panjwani D, Persad DL, Minhas GS, Daar AS, Singh JA, Singer PA (2008) Public engagement on global health challenges. BMC Public Health 8(168):e021517

Cortassa C (2016) In science communication, why does the idea of a public deficit always return? The eternal recurrence of the public deficit. Public Underst Sci 25(4):447-459

Creswell JW, Plano Clark VL, Garrett AL (2008) Methodological issues in conducting mixed methods research designs. In: Bergman MM (ed.) Advances in mixed methods research. Sage, London, pp. 66-84

Dalrymple L (2006) Has it made a difference? Understanding and measuring the impact of applied theatre with young people in the South African context. Res Drama Educ: J Appl Theatre Perform 11(2):201-218

Davis $\mathrm{M}$, Whittaker A, Lindgren M, Djerf-Pierre M, Manderson L, Flowers $\mathrm{P}$ (2017) Understanding media publics and the antimicrobial resistance crisis. Glob Public Health 13(9):1158-1168

Dawson E (2018) Reimagining publics and (non)participation: exploring exclusion from science communication through the experiences of low-income, minority ethnic groups. Public Underst Sci 27(7):772-786

Department of Health (2013) UK five year antimicrobial resistance strategy: 2013 to 2018. Department of Health, London

Dobility Inc. (2017) SurveyCTO. Dobility Inc, Cambridge

Etherton M, Prentki T (2006) Drama for change? Prove it! Impact assessment in applied theatre. Res Drama Educ 11(2):139-155

Galloway S (2009) Theory-based evaluation and the social impact of the arts. Cult Trends 18(2):125-148

Gelband H, Miller-Petrie M, Pant S, Gandra S, Levinson J, Barter D, White A, Laxminarayan R (2015) State of the world's antibiotics, 2015. Center for Disease Dynamics, Economics \& Policy, Washington

Google Inc. (2017) Google maps. http://maps.google.com. Accessed 17 June 2017

Government of Thailand (1967) พระราชบัญญัติยา พ.ศ. 2510 [Drug Act, B.E. 2510 (1967)]. http://taxclinic.mof.go.th/pdf/75FBD1F3_192F_18D9_E3BA_683D5 430DC9E.pdf. Accessed 20 Dec 2018

Government of Thailand (2018) เรื่อง ยาอันตราย ฉบับที่ ๓๐ [Dangerous drugs, Notice No. 30]. http://www.fda.moph.go.th/sites/drug/Shared\%20Documents/ Law03-TheMinistryOfHealth/Dangerousdrugs(30).PDF

Greer RC, Intralawan D, Mukaka M, Wannapinij P, Day NPJ, Nedsuwan S, Lubell $Y(2018)$ Retrospective review of the management of acute infections and the indications for antibiotic prescription in primary care in northern Thailand. BMJ Open, 8(e022250):e021517

Haddon A (2006) A long story with a happy ending. Res Drama Educ 11 (2):185-199

Haenssgen MJ, Ariana P (2017) Healthcare access: a sequence-sensitive approach. SSM-Popul Health 3:37-47

Haenssgen MJ, Charoenboon N, Althaus T, Greer RC, Intralawan D, Lubell Y (2018a) The social role of C-reactive protein point-of-care testing to guide antibiotic prescription in Northern Thailand. Soc Sci Med 202:1-12

Haenssgen MJ, Charoenboon N, Zanello G, Mayxay M, Reed-Tsochas F, Jones $\mathrm{COH}$, Kosaikanont R, Praphattong P, Manohan P, Lubell Y, Newton PN, Keomany S, Wertheim HFL, Lienert J, Xayavong T, Warapikuptanun $\mathrm{P}$, Khine Zaw Y, U-thong P, Benjaroon P, Sangkham N, Wibunjak K, Chai-in P, Chailert S, Thavethanutthanawin P, Promsutt K, Thepkhamkong A, Sithongdeng N, Keovilayvanh M, Khamsoukthavong N, Phanthasomchit P, Phanthavong C, Boualaiseng S, Vongsavang S, Greer RC, Althaus T, Nedsuwan S, Intralawan D, Wangrangsimakul T, Limmathurotsakul D, Ariana P (2018b) Antibiotics and activity spaces: protocol of an exploratory study of behaviour, marginalisation, and knowledge diffusion. BMJ Glob Health 3 (e000621):e021517

Hamlyn B, Shanahan M, Lewis H, O'Donoghue E, Hanson T, Burchell K (2015) Factors affecting public engagement by researchers: a study on behalf of a consortium of UK public research funders. TNS, London 
Hawkings NJ, Wood F, Butler CC (2007) Public attitudes towards bacterial resistance: a qualitative study. J Antimicrob Chemother 59(6):1155-1160

Holloway KA, Batmanabane G, Puri M, Tisocki K (2017) Antibiotic use in South East Asia and policies to promote appropriate use: reports from country situational analyses. BMJ 358(Suppl. 1):e021517

Howard SJ, Catchpole M, Watson J, Davies SC (2013) Antibiotic resistance: global response needed. Lancet Infect Dis 13(12):1001-1003

Khine Zaw Y, Charoenboon N, Haenssgen MJ, Lubell Y (2018) A comparison of patients' local conceptions of illness and medicines in the context of Creactive protein biomarker testing in Chiang Rai and Yangon. Am J Trop Med Hyg 98(6):1661-1760

Kilroy A, Garner C, Parkinson C, Kagan C, Senior P (2007) Towards transformation: exploring the impact of culture, creativity and the arts on health and wellbeing. Manchester Metropolitan University, Manchester

Ko $\mathrm{H}$ (2016) In science communication, why does the idea of a public deficit always return? How do the shifting information flows in healthcare affect the deficit model of science communication? Public Underst Sci 25(4):427-432

Lafrenière D, Cox SM (2013) 'If you can call it a poem': toward a framework for the assessment of arts-based works. Qual Res 13(3):318-336

Lambert H (2016) 'The rhetoric of resistance', Social science research for understanding drug resistant infections. http://amrchamp.blogs.ilrt.org/2016/09/ 21/the-rhetoric-of-resistance/. Accessed 21 July 2017

Ledgard A (2013) Blood makes noise: evaluation. http://annaledgard.com/wpcontent/uploads/BMNReport1.pdf

Ledgard A (2016) Under the microscope: evaluation report. http://annaledgard. com/wp-content/uploads/UtMEvalReport-FINAL3.5.16small-1.pdf

Leshner AI (2003) Public engagement with science. Science 299(5609):977-977

Lieblich A, Tuval-Mashiach R, Zilber T (1998) Narrative research: reading, analysis and interpretation. Sage, Thousand Oaks

Lim R, Peto TJ, Tripura R, Cheah PY (2016) Village drama against malaria. Lancet 388(10063):2990

Mendelson M, Balasegaram M, Jinks T, Pulcini C, Sharland M (2017) Antibiotic resistance has a language problem. Nature 545(7652):23-25

Meyer G (2016) In science communication, why does the idea of a public deficit always return? Public Underst Sci 25(4):433-446

Nerlich B, James R (2009) "The post-antibiotic apocalypse" and the "war on superbugs": catastrophe discourse in microbiology, its rhetorical form and political function. Public Underst Sci 18(5):574-590

Nyirenda D, Makawa TC, Chapita G, Mdalla C, Nkolokosa M, O'byrne T, Heyderman R, Desmond N (2018) Public engagement in Malawi through a health-talk radio programme 'Umoyo nkukambirana': a mixed-methods evaluation. Public Underst Sci 27(2):229-242

OECD Development Assistance Committee (1991) Principles for evaluation of development assistance. Organisation for Economic Co-operation and Development, Paris

OECD Development Assistance Committee (2010) Evaluating development cooperation: Summary of key norms and standards. Organisation for Economic Co-operation and Development, Paris

Park H, Sha MM, Pan Y (2014) Investigating validity and effectiveness of cognitive interviewing as a pretesting method for non-English questionnaires: findings from Korean cognitive interviews. Int J Soc Res Methodol 17(6):643-658

Park P (1999) People, knowledge, and change in participatory research. Manag Learn 30(2):141-157

Pearce W, Raman S, Turner A (2015) Randomised trials in context: practical problems and social aspects of evidence-based medicine and policy. Trials 16 (394): $\mathrm{e} 021517$

Peglidou A (2010) Therapeutic itineraries of 'depressed' women in Greece: power relationships and agency in therapeutic pluralism. Anthropol Med 17(1):41-57

Peter C, Koch T (2016) When debunking scientific myths fails (and when it does not): the backfire effect in the context of journalistic coverage and immediate judgments as prevention strategy. Sci Commun 38(1):3-25

Research Councils UK (2011) Concordat for engaging the public with research. Research Councils UK, Swindon

Retzbach A, Maier M (2014) Communicating scientific uncertainty. Commun Res 42(3):429-456

Roh S, Rickard LN, McComas KA, Decker DJ (2018) Public understanding of One Health messages: the role of temporal framing. Public Underst Sci 27(2):185-196

Simba D, Kakoko D, Semali I, Kessy A, Embrey M (2016) Household knowledge of antimicrobials and antimicrobial resistance in the wake of an Accredited Drug Dispensing Outlet (ADDO) program rollout in Tanzania. PLoS ONE 11 (e0163246):e021517

Skinner D, Metcalf CA, Seager JR, De Swardt JS, Laubscher JA (1991) An evaluation of an education programme on HIV infection using puppetry and street theatre. AIDS Care 3(3):317-329
Sringernyuang L (2000) Availability and use of medicines in rural Thailand. Ph.D. thesis, Amsterdam Institute for Social Science Research, Amsterdam.

StrataCorp. (2013) Stata statistical software: release 13. StataCorp LP, College Station

Stilgoe J, Lock SJ, Wilsdon J (2014) Why should we promote public engagement with science? Public Underst Sci 23(1):4-15

Suldovsky B (2016) In science communication, why does the idea of the public deficit always return? Exploring key influences. Public Underst Sci 25 (4):415-426

Tangcharoensathien V, Sattayawutthipong W, Kanjanapimai S, Kanpravidth W, Brown R, Sommanustweechai A (2017) Antimicrobial resistance: from global agenda to national strategic plan, Thailand. Bull World Health Organ 95 (8):599-603

Tangcharoensathien V, Sommanustweechai A, Chanvatik S, Kosiyaporn H, Tisocki K (2018) Addressing the threat of antibiotic resistance in Thailand: monitoring population knowledge and awareness. WHO South-East Asia J Public Health 7(2):73-78

The Review on Antimicrobial Resistance (2016) Tackling drug-resistant infections globally: final report and recommendations. The UK Prime Minister, London

Thomson P, Sanders J, Bloomfield J (2013) Performing impact: a scoping study of the ways in which community theatre understands and evaluates work University of Nottingham, Nottingham

Tindana PO, Singh JA, Tracy CS, Upshur REG, Daar AS, Singer PA, Frohlich J, Lavery JV (2007) Grand challenges in global health: community engagement in research in developing countries. PLoS Med 4(e273):e021517

Villalonga-Olives E, Kawachi I (2017) The dark side of social capital: a systematic review of the negative health effects of social capital. Soc Sci Med 194:105-127

WHO (2015) Global action plan on antimicrobial resistance. World Health Organization, Geneva

WHO (2016) World antibiotic awareness week: 2016 campaign toolkit. World Health Organization, Geneva

WHO, FAO and OIE (2018) Monitoring global progress on addressing antimicrobial resistance: analysis report of the second round of results of AMR country self-assessment survey 2018. World Health Organization, Food and Agriculture Organization of the United Nations and World Organisation for Animal Health (OIE), Geneva

WHO SEARO (2016) Medicines in health care delivery: Thailand: situational analysis: 23 November-4 December 2015. World Health Organization, Regional Office for South East Asia, New Delhi

Willis GB (2005) Cognitive interviewing: a tool for improving questionnaire design Sage, Thousand Oaks

Wilson C, Manners P, Duncan S (2014) Building an engaged future for UK higher education: full report from the Engaged Futures consultation. National Coordinating Centre for Public Engagement, Bristol

\section{Additional information}

Supplementary information The online version of this article (https://doi.org/10.1057/ s41599-019-0226-9) contains supplementary material, which is available to authorised users.

Competing interests: The authors declare no competing interests.

Reprints and permission information is available online at http://www.nature.com/ reprints

Publisher's note: Springer Nature remains neutral with regard to jurisdictional claims in published maps and institutional affiliations.

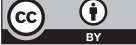

Open Access This article is licensed under a Creative Commons Attribution 4.0 International License, which permits use, sharing, adaptation, distribution and reproduction in any medium or format, as long as you give appropriate credit to the original author(s) and the source, provide a link to the Creative Commons license, and indicate if changes were made. The images or other third party material in this article are included in the article's Creative Commons license, unless indicated otherwise in a credit line to the material. If material is not included in the article's Creative Commons license and your intended use is not permitted by statutory regulation or exceeds the permitted use, you will need to obtain permission directly from the copyright holder. To view a copy of this license, visit http://creativecommons.org/ licenses/by/4.0/.

() The Author(s) 2019 
Nutcha Charoenboon (1) ', Marco J. Haenssgen ${ }^{1,2,3,4,5}$, Penporn Warapikuptanun', Thipphaphone Xayavong ${ }^{6,7,8} \&$ Yuzana Khine Zaw ${ }^{9}$

${ }^{1}$ Mahidol Oxford Tropical Medicine Research Unit, Faculty of Tropical Medicine, Mahidol University, 3/F, 60th Anniversary Chalermprakiat Building, 420/6 Rajvithi Road, Bangkok 10400, Thailand. ${ }^{2}$ Centre for Tropical Medicine and Global Health, Nuffield Department of Clinical Medicine, University of Oxford, Old Road Campus, Roosevelt Drive, Oxford OX3 7FZ, UK. ${ }^{3}$ CABDyN Complexity Centre, Saïd Business School, University of Oxford, Park End Street, Oxford OX1 1HP, UK. ${ }^{4}$ Green Templeton College, 43 Woodstock Road, Oxford OX2 6HG, UK. ${ }^{5}$ Global Sustainable Development, School for Cross-faculty Studies, University of Warwick, Coventry CV4 7AL, UK. ${ }^{6}$ Department of Peace and Conflict Studies, University for Peace, P.O. Box 138-6100San José, Costa Rica. ${ }^{7}$ Department of Political Science, School of Social Science, Ateneo de Manila University, 1108 Metro Manila, Quezon City, Philippines. ${ }^{8}$ Lao Oxford Mahosot Wellcome Trust Research Unit (LOMWRU), Mahidol Oxford Tropical Medicine Research Unit (MORU), Faculty of Tropical Medicine, Mahidol University, Bangkok 10400, Thailand. ${ }^{9}$ Department of Global Health and Development, London School of Hygiene \& Tropical Medicine, Keppel Street, London WC1E 7HT, UK 